\title{
Phonological working memory is adversely affected in adults with anorexia nervosa: a systematic literature review
}

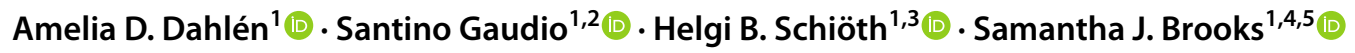

Received: 29 October 2021 / Accepted: 18 January 2022 / Published online: 8 February 2022

(c) The Author(s) 2022

\begin{abstract}
Purpose Cognitive restraint has potentiating and deleterious effects on working memory (WM) in anorexia nervosa (AN). Conflicting evidence may be due to heterogeneity of tasks examining different WM components (e.g., verbal/auditory versus visuospatial), and differences in adolescent versus adult AN. Additionally, differential cognitive profiles of restricting versus binge/purging subtypes, comorbid psychiatric disorders and psychotropic medication use may confound findings.

Methods To address these conflicts, 25 studies, published between 2016 and 2021, investigating WM in children, adolescents and adults with AN were systematically reviewed using PRISMA guidelines.

Results In $71 \%$ of WM tasks, no difference in performance between AN patients and age-matched controls was reported, while $29 \%$ of WM tasks showed worse performance. Adults with AN displayed deficits in $44 \%$ of the verbal/auditory tasks, while performance remained unaffected in $86 \%$ of visuospatial tasks.

Conclusion Examining age groups and WM subsystems separately revealed novel findings of differentially affected WM components in AN. Comorbidities and psychotropic medications were common among AN participants and should be regarded as critical confounding factors for WM measures. Future studies examining different components of WM, acknowledging these confounding factors, may reveal specific deficits in AN to aid treatment improvement strategies.
\end{abstract}

Level of evidence I, systematic review.

Keywords Working memory $\cdot$ Eating disorder $\cdot$ Phonological loop $\cdot$ Visuospatial sketchpad $\cdot$ Anorexic voice

\section{Introduction}

Amelia D. Dahlén

dahlenamelia@gmail.com

Samantha J. Brooks

S.J.Brooks@1jmu.ac.uk

1 Section of Functional Pharmacology, Department of Neuroscience, Uppsala University, 75124 Uppsala, Sweden

2 Department of Biomedicine and Prevention, University of Rome Tor Vergata, 00133 Rome, Italy

3 Institute of Translational Medicine and Biotechnology, I. M. Sechenov First Moscow State Medical University, Moscow, Russia

4 School of Psychology, Faculty of Health, Liverpool John Moores University, Liverpool, UK

5 Neuroscience Research Laboratory (NeuRL), Department of Psychology, School of Human and Community Development, University of the Witwatersrand, Johannesburg, South Africa
Anorexia nervosa (AN) is an eating disorder (ED) characterised by self-induced emaciation, distorted body image and fear of gaining weight [1]. It also involves strict monitoring of food intake to control body shape, so-called cognitive restraint [2]. The disorder typically emerges in adolescent females and is known for its unremitting treatment resistance throughout the individual's lifetime [3, 4]. Alongside the medical complications elicited by long-term starvation, AN patients have a high risk of developing affective disorders, personality disorders and substance use disorders [5]. The physical and psychological deterioration in AN tragically causes the highest mortality rate of all psychiatric disorders [6].

Although the aetiology of AN remains largely unknown, a high degree of cognitive restraint coinciding with perfectionism, rigid thinking styles and obsessive-compulsive cognitions generally set $\mathrm{AN}$ apart from other EDs, such as Bulimia Nervosa (BN) and Binge Eating Disorder 
(BED) [7, 8]. However, it is important to note that an individual's diagnosis may change over the course of illness-often referred to as trans-diagnostic $[9,10]$. There are several cognitive theories regarding how excessive cognitive control is preserved. One such hypothesis is that variation in working memory (WM) capacity contributes to the obsessive, ruminative and inflexible thought patterns that appear to underlie fluctuating cognitive deficits, appetite restraint and body image distortion in restrictive AN (AN-R) [11-14]. A milder degree of restraint may explain the binge-purging subtype of AN (AN-BP) and the progression into binge-purge and bulimia symptoms, where weight-compensatory behaviours are interleaved with bouts of impulsive and excessive food intake [7].

WM is a crucial executive function responsible for holding and manipulating verbal, auditory and visuospatial information after it is no longer present as a cue $[15,16]$. This enables future goals to be achieved despite challenge from distractions [16]. Baddeley and Hitch (1974) postulate that verbal and auditory information are processed by a compartment referred to as the phonological loop (e.g., an inner voice) and that visual information is processed by the visuospatial scratchpad (e.g., contributing to body image). These separate subsystems work in concert with the central executive coordinating system [15]. Unlike the single-component visuospatial sketchpad, the phonological loop can be further separated into the phonological store and the articulatory rehearsal process [17]. The former holds speech-based information for approximately $2 \mathrm{~s}$, whereas the latter prevents subsequent decay through subvocal speech rehearsal [17]. Against this background, tasks utilising the phonological loop, e.g., story recall, may give rise to different results than tasks engaging the visuospatial domain, e.g., Rey Complex Figure Task [18].

In individuals with AN, WM is suggested to be disproportionately engaged in negative ruminations about the self, past negative emotional experiences and preoccupations with food and eating [19]. While an excessive activation of WM processes associated with appetite restraint in AN has been suggested to improve overall WM performance in patients [13], a pathological preoccupation with AN-related cues could also have detrimental effects on WM tasks [20]. The potential role of WM processes in the development and maintenance of AN parallels the notion of a controlling internal dialogue first described by Bruch in 1978 [21] and later referred to as the anorexic voice [22, 23]. An estimated $96 \%$ of individuals with ED reportedly experience this critical inner voice, which is increasingly perceived as controlling throughout the duration of AN $[24,25]$. This supports the concept of a verbal cognitive restraint framework for the disorder, where weight is lost through a compulsive adherence to fasting, purging and excessive exercise regimens, which is extremely difficult to alter during clinical intervention [26].

Over the past two decades, there have been several publications exploring altered WM capacity as a cognitive hallmark of AN. Between 2002 and 2015, 45\% of the studies reported an enhanced WM performance in AN cohorts, $18 \%$ reported deficits while the remaining 37\% reported no statistically significant difference from healthy controls [14]. A year later, six reviewed studies examining WM in AN suggested deficits or equal WM performance in AN compared to controls [26]. Given the involvement of WM in cognitive inhibition, goal-orientation and other executive functions associated with core deficits in AN, factors that may confound the findings, such as participant age, disorder subtypes, illness duration, comorbidities and the type of WM tasks used, should be considered as contributing to discrepancies in research findings [28-30].

The purpose of the current review is to systematically examine the literature on WM capacity in AN, published between 2016 and 2021, to provide an updated and more nuanced perspective on the role of WM in AN. Considering possible confounding factors that can affect WM performance, this review aims to provide a more focused account of (a) the specific memory tasks used in line with different subcomponents of WM, i.e. phonological and visuospatial measures, (b) the age group of participants, (c) the AN subtypes included and (d) any psychiatric co-morbidities and medications present in the participant samples.

\section{Methods}

This review followed the Preferred Reporting Items for Systematic Reviews and Meta-Analysis (PRISMA) guidelines [31] (Fig. 1). The PRISMA checklist of recommended items to be reported can be found in Online Resource Table S1.

\section{Search strategy and inclusion criteria}

For the literature search, PubMed, ScienceDirect, Scopus, Web of Science and Google Scholar were employed. The publication time-frame was limited to January 2016-October 2021 (from the end of the previous review search period, Brooks et al. (2017) [26], to the present) and the following search terms were used in each database search: anorexia AND working memory; anorexia nervosa AND working memory; anorexia nervosa AND working memory AND cognitive control; anorexia nervosa AND cognitive control; anorexia nervosa AND memory. The reference lists of the studies were inspected and skilled colleagues within the AN field were consulted for additional relevant papers. The inclusion criteria were peer-reviewed papers that were (1) written in English, (2) included participants with current or 


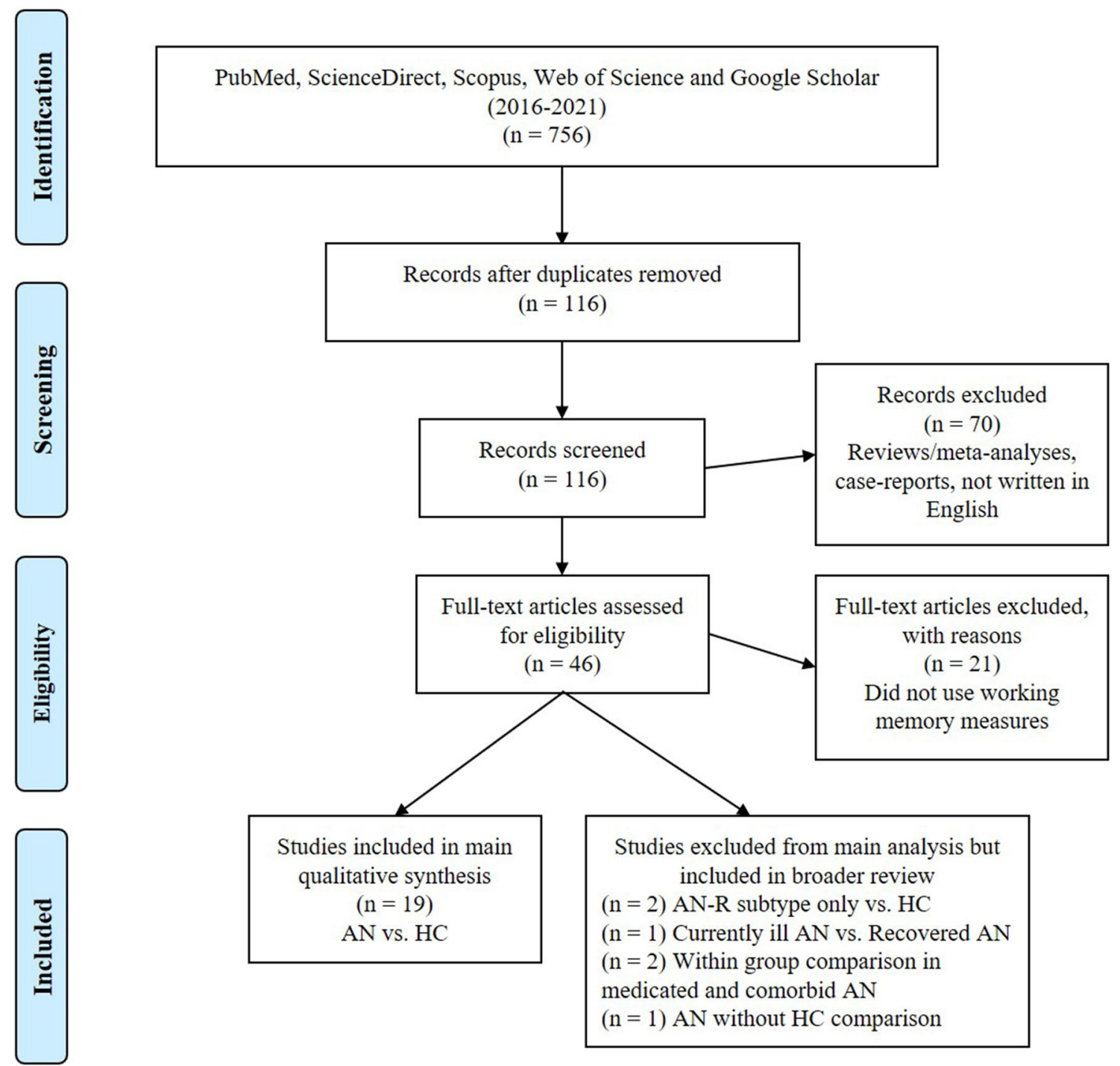

Fig. 1 PRISMA Flow Diagram of the relevant steps for the literature search

recovered diagnosed $\mathrm{AN}$, (3) utilised a minimum of one WM measure, (4) published in peer-reviewed journals. Exclusion criteria were (1) articles not in English, (2) systematic reviews/meta-analysis, book chapters, and perspective articles, (3) research articles not investigating WM, (4) case reports. Authors of eligible primary studies were contacted to obtain additional information if poorly reported.

\section{Quality assessment and data abstraction}

To prevent selection bias, the PRISMA recommendations for systematic literature analysis have been followed and two authors (A.D.D. and S.J.B.) selected studies based on the broad search terms. Risk of bias in individual studies was assessed using the AXIS appraisal tool [32] (Online Resource Table S2). The following characteristics were extracted: type of WM measures used, sample size of ED and healthy control (HC) participants, age, body mass index (BMI), illness duration, subtype of AN, co-occurring psychopathology and medications (Tables 1,2). The extracted WM tasks were categorised according to the verbal/auditory or visuospatial domain (Online Resource Tables S3, S4). As the aim was to provide a review of variables that may influence $\mathrm{WM}$ in $\mathrm{AN}$, factors, such as AN subtypes, psychiatric comorbidities and pharmacological interventions, were not excluded. The heterogeneity of the obtained publications prevented a meta-analysis to be conducted. 


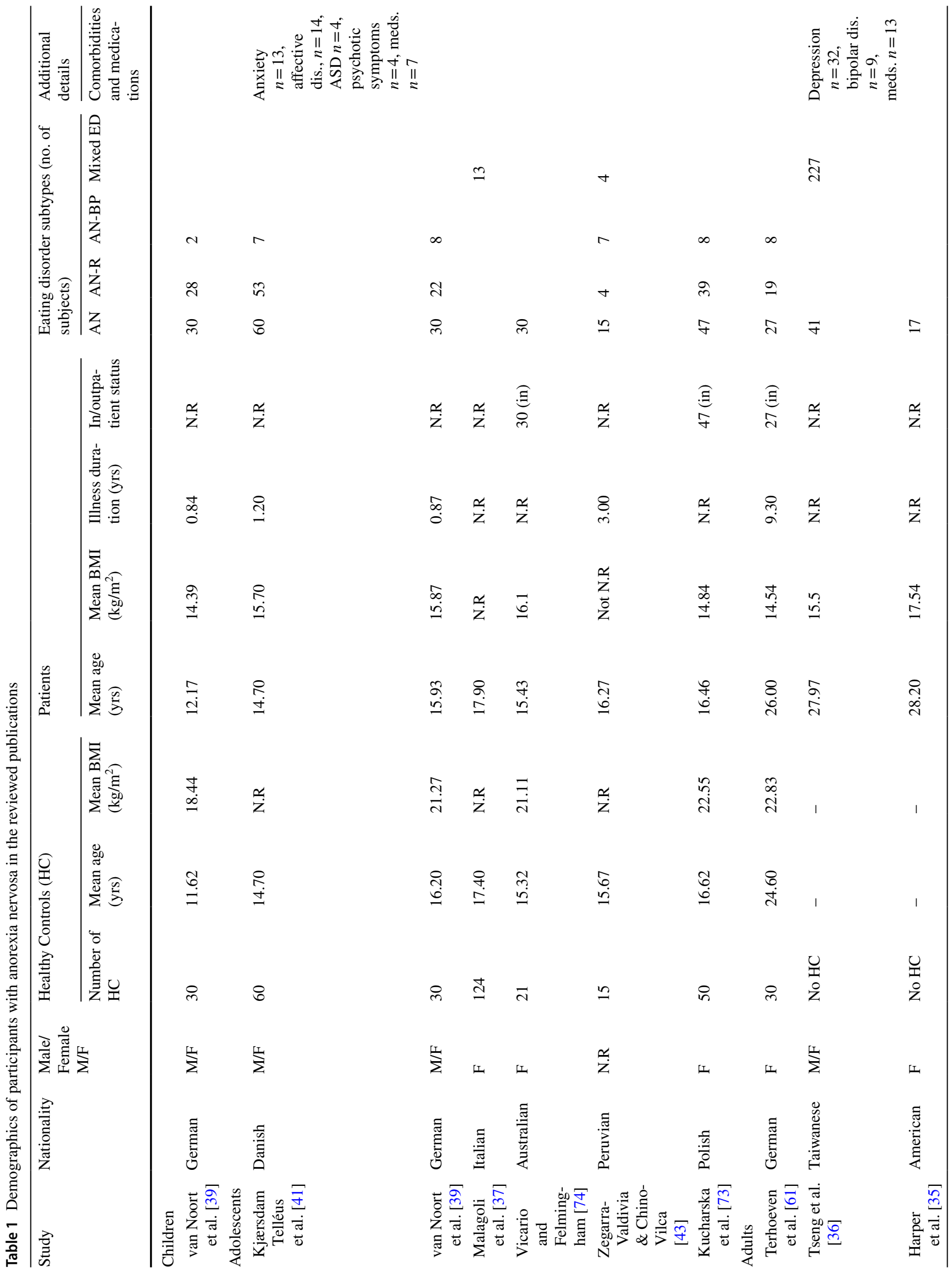




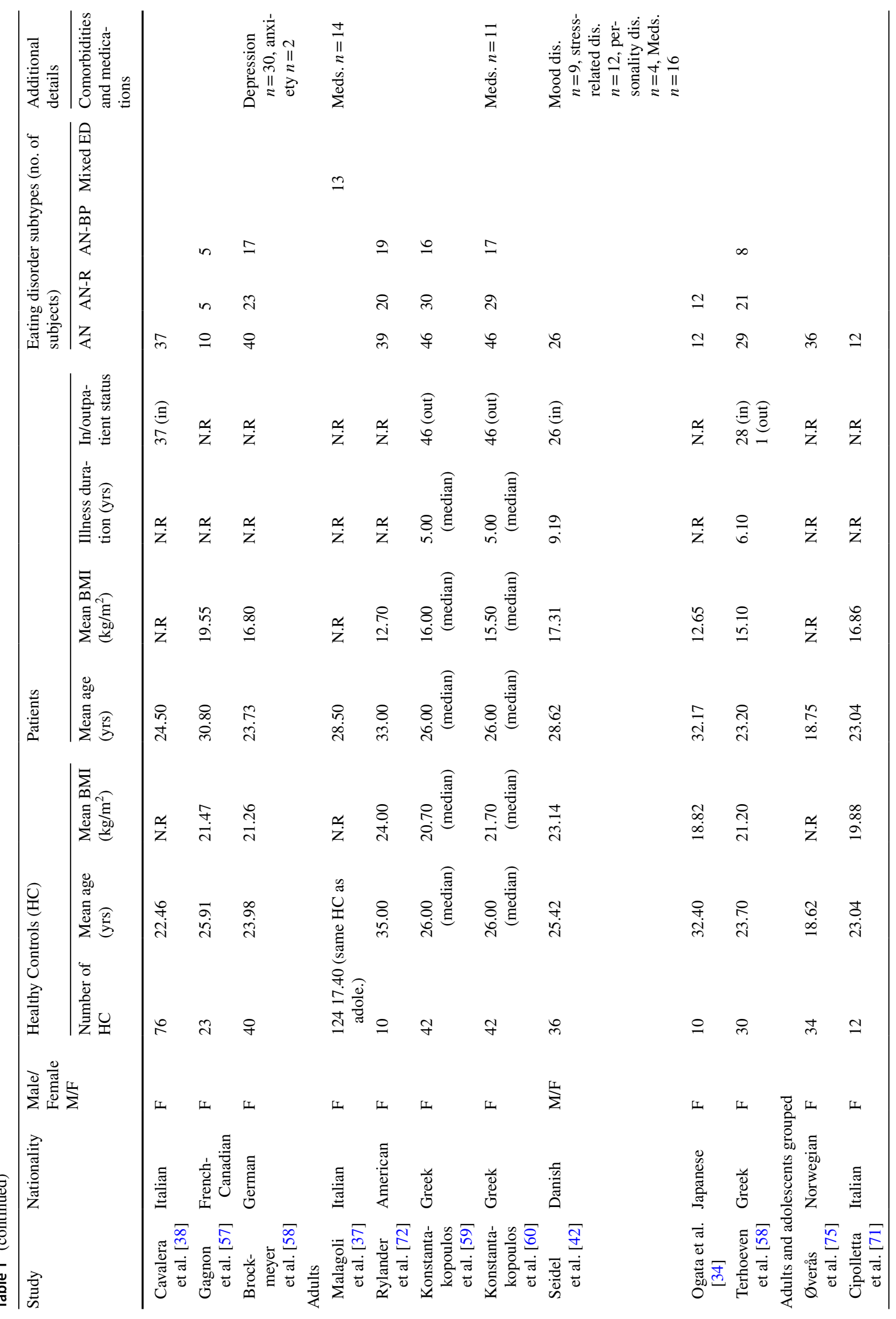




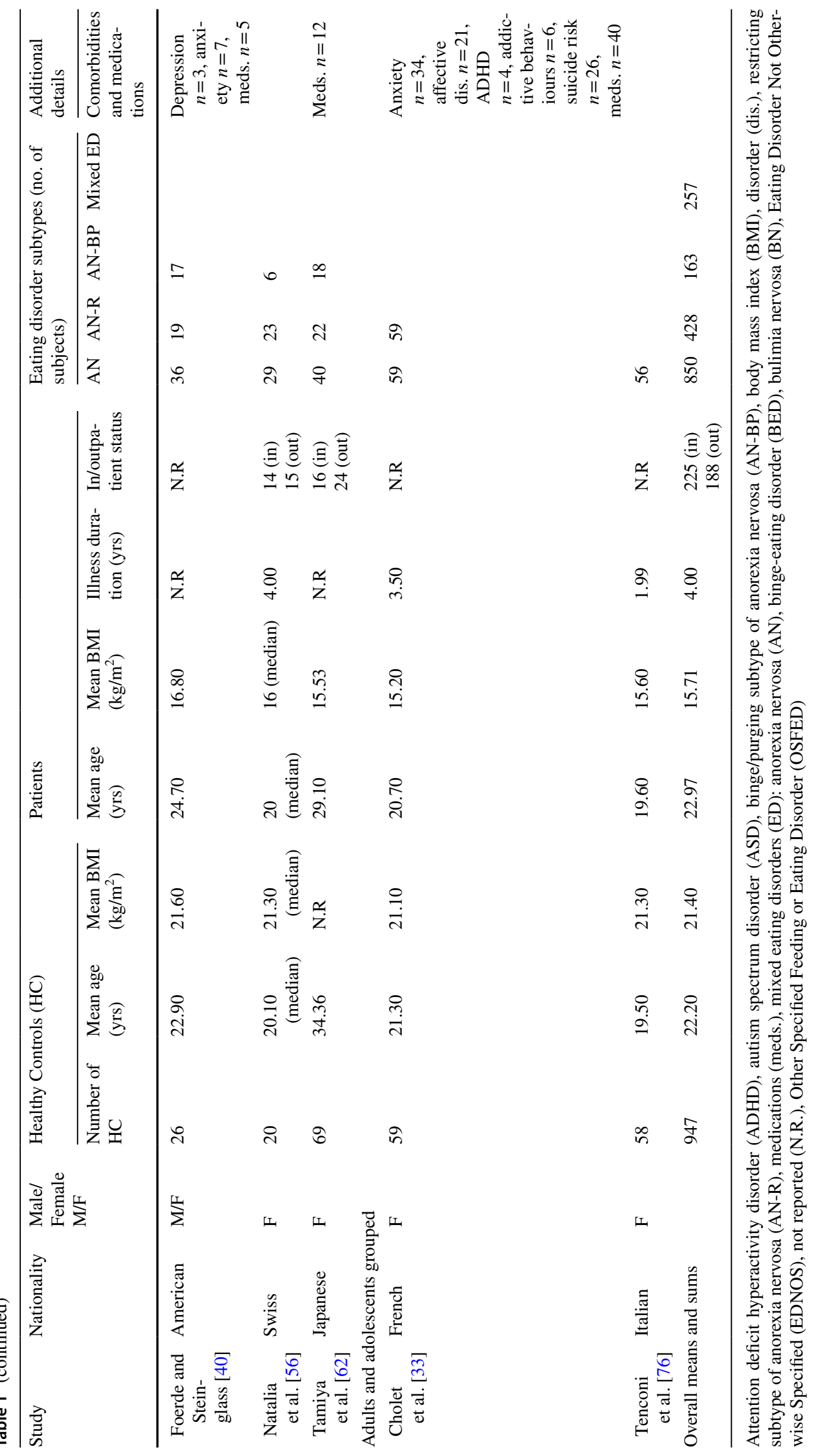




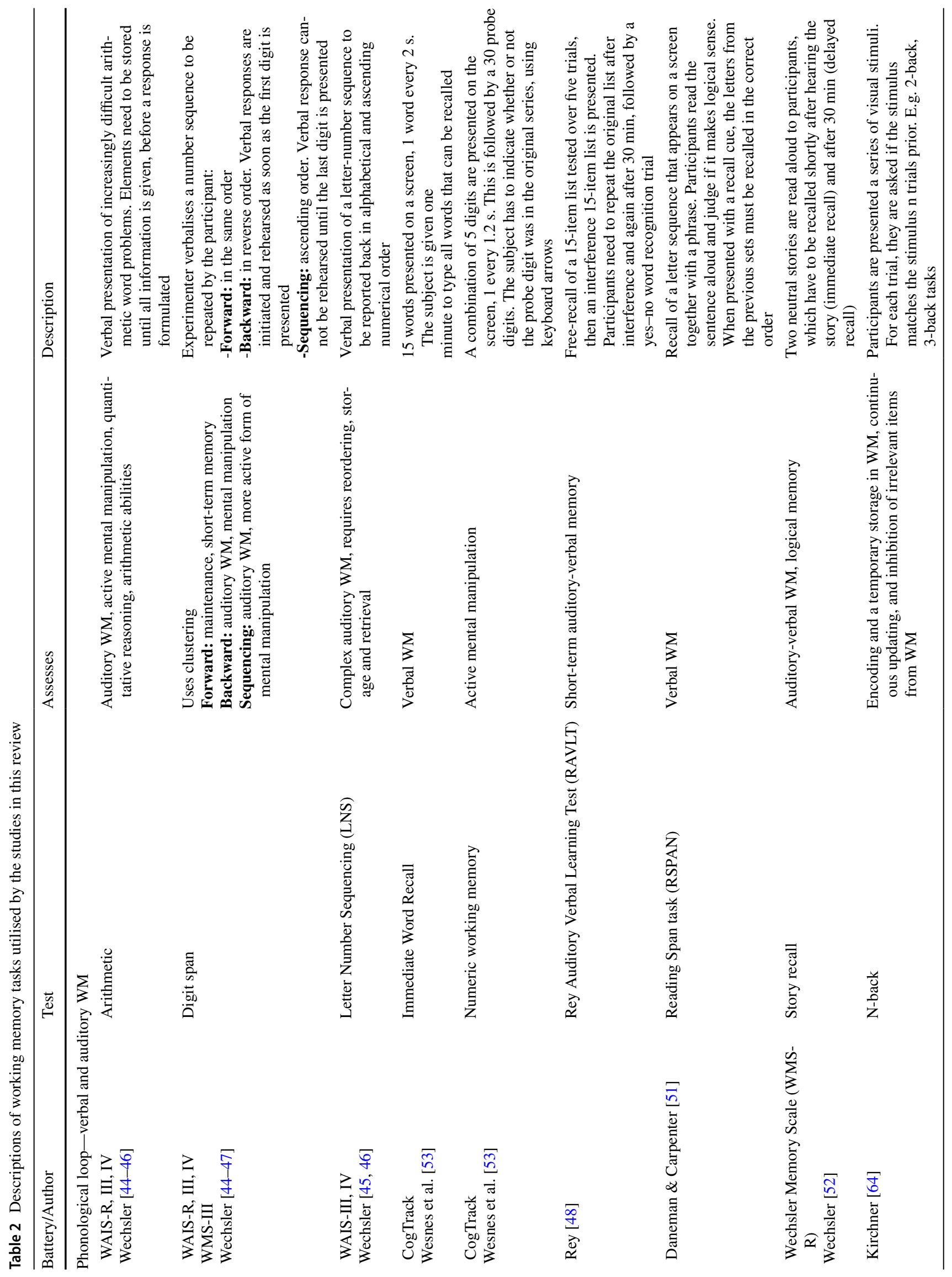




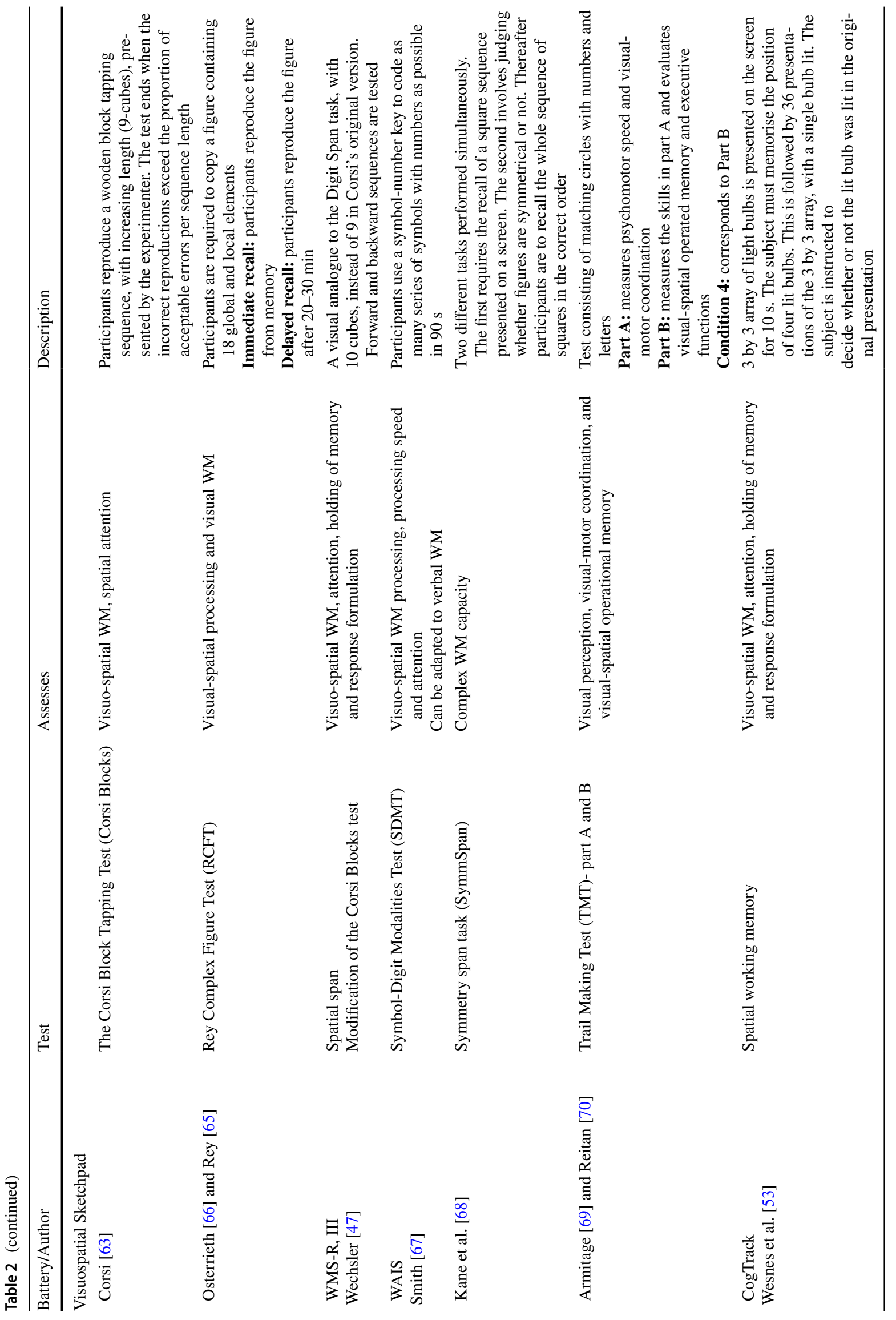




\section{Results}

The literature search yielded 25 studies examining WM capacity in AN across 14 countries, 19 of which were case versus control studies and formed the main analysis. The remaining six studies examined WM within AN-R [33, 34], pre-and post-recovered AN [35], comorbid and medicated ED [36, 37] or did not perform statistical comparisons between the clinical ED and non-clinical HC groups [38] (Table 3). The combined sample size included $850 \mathrm{AN}$ participants with a mean age of 23 years and a mean BMI of 15.7. The patient sample sizes of individual studies ranged from $n=10$ to $n=60$. The combined HC sample size was 947 with a mean age of 22.2 years. BMI values for the HC were not consistently reported but for the 18 studies that did, the mean BMI was 21.4 (Table 1). 19 of the studies exclusively included female participants, with the exception of the mixed gender groups in five studies [36, 39-42]. ZegarraValdivia and Chino-Vilca [43] did not specify the genders of their sample. Of the ten publications which reported patient status, 225 were inpatients while 188 were outpatients. The subsequent sections will elaborate on 1) memory performance across tasks, 2) differential WM performance according to age groups, 3) WM in the subtypes of AN, 4) psychiatric comorbidities and 5) psychotropic medications among the AN participants.

\section{General working memory performance across all tasks}

Sixteen commonly used WM measures were identified (Table 2). Among the 19 publications performing statistical comparisons between AN and HC groups, a total of $n=38$ independent WM tasks were conducted across all studies. AN participants exhibited impairments in $28.9 \%$ of the WM tasks while their performance was unaffected in $71.1 \%$ (Fig. 2A).

\section{Verbal and auditory domains}

These included Arithmetic, verbal Digit span, Letter Number Sequencing (LNS) [44-47], Rey Auditory Verbal Learning Test (RAVLT) [48] (and its German equivalent the Verbal Learning and Memory Test (VLMT) [49, 50], Reading Span task (RSPAN) [51], Story recall [52], Numeric WM and Immediate Word Recall [53] (Online Resource Table S3). $\mathrm{AN}$ and $\mathrm{HC}$ groups were compared in $n=14$ verbal/auditory tasks, with a total sample size of $n=717$ (Fig. 2). The scores from Arithmetic and Digit span subsets of the WAISIV battery were summed to create a Working Memory Index (WMI) [54]. The backwards verbal digit span was the most recurring measure utilising the phonological loop. Of the studies directly comparing $\mathrm{AN}$ and $\mathrm{HC}$ cohorts in the verbal digit span, $57 \%$ of the studies did not detect any significant difference between the groups [55-58], while $43 \%$ found impairments in the AN participants [43, 59, 60] (Fig. 2B). Zegarra-Valdivia and Chino-Vilca [43] also highlighted a significant correlation between illness duration and poorer performance in the verbal/auditory digit span. Cavalera et al. [38] did not perform direct statistical comparisons between $\mathrm{AN}$ and $\mathrm{HC}$ groups, but put forward the notion that the feeling of shame, elicited by writing about an unpleasant experience in between digit span tests, has a stronger negative effect on performance in AN, BN, and Other Specified Feeding or Eating Disorder (OSFED) populations than in HC. Moreover, Terhoeven et al. [56] and Natalia et al. [61] both presented immediate recall deficits in RAVLT/VLMT for the AN group. Furthermore, Terhoeven et al. [61] measured significantly worse performance among AN participants in the immediate story recall. For the LNS, numeric WM and immediate word recall no significant differences between the AN and HC samples were detected [40, 42, 62]. Overall, the AN population had worse WM performance in $42.9 \%$ of the verbal/auditory tasks, when compared to $\mathrm{HC}$, and performed at comparable levels to $\mathrm{HC}$ in the remaining $57.1 \%$ (Fig. 2A).

\section{Visuospatial domains}

These included, the Corsi Block Tapping Test [63] (and its modification the Spatial span [47]), visuospatial Digit span [44-47], N-back [64], Rey Complex Figure Test (RCFT) [65, 66], Symbol-Digit Modalities Test (SDMT) [67], Symmetry span task (SymmSpan) [68], Trail Making Test (TMT) [69, 70], and Spatial WM [53] (Online Resource Table S4). AN and $\mathrm{HC}$ groups were compared in $n=24$ visuospatial tasks, with a total sample size of $n=1016$ (Fig. 2). When measuring visuospatial WM, the TMT was the most common task, followed by the Corsi Blocks/Spatial span and the RCFT (Online Resource Table S4). AN and HC groups tended to perform at similar levels across the three measures with no significant difference found in $70 \%$ of the studies using the TMT, $80 \%$ of the Corsi blocks/Spatial span studies and in $80 \%$ of the RCFT studies [39-41, 56, 57, 61, 62, 71, 72, 74-76] (Fig. 2B). Natalia et al. [56] reported worse performance for individuals with $\mathrm{AN}$ in the backwards condition of the Corsi Blocks/Spatial span and in the TMT. Similarly, Kucharska et al. [73] and Terhoeven et al. [58] found TMT impairments in their AN sample compared to the HC. In contrast, no significant difference emerged in the visuospatial digit span [74], spatial WM task [42] n-back or SDMT [56]. The currently ill AN (AN-CC) group of Harper et al. [35] demonstrated an impaired TMT-B performance in comparison to recovered AN (AN-CR). However, the groups 
Table 3 Overview of the working memory modalities and sample sizes of the reviewed studies

\begin{tabular}{|c|c|c|}
\hline $\begin{array}{l}\text { Both verbal/auditory and visuospatial (Total } \\
n=431, \mathrm{AN}, n=197, \mathrm{HC}, n=234 \text { ) }\end{array}$ & Verbal/auditory (Total $n=286, \mathrm{AN}, n=147, \mathrm{HC}, n=139$ ) & $\begin{array}{l}\text { Visuospatial (Total } n=585 \text {, } \\
\text { AN, } n=275, \mathrm{HC}, n=310 \text { ) }\end{array}$ \\
\hline \multicolumn{3}{|l|}{ Main analysis of case versus control studies } \\
\hline Terhoeven et al. [61] & Zegarra-Valdivia \& Chino-Vilca [43] & van Noort et al. [39] \\
\hline Foerde and Steinglass [40] & Brockmeyer et al. [58] & Kjærsdam Telléus et al. [41] \\
\hline Natalia et al. [56] & Konstantakopoulos et al. [59] & Cipolletta et al. [71] \\
\hline Tamiya et al. [62] & Konstantakopoulos et al. [60] & Øverås et al. [75] \\
\hline Gagnon et al. [57] & & Vicario and Felmingham [74] \\
\hline Seidel et al. [42] & & Kucharska et al. [73] \\
\hline \multirow[t]{2}{*}{ Terhoeven et al. [58] } & & Rylander et al. [72] \\
\hline & & Tenconi et al. [76] \\
\hline $\begin{array}{l}\text { Both verbal/auditory and visuospatial (Total } \\
n=255, \mathrm{ED}, n=72, \mathrm{HC}, n=183 \text { ) }\end{array}$ & Verbal/auditory (Total $n=176, \mathrm{ED}, n=90, \mathrm{HC}, n=86$ ) & $\begin{array}{l}\text { Visuospatial (Total } n=17 \text {, } \\
\mathrm{ED}, n=17 \text { ) }\end{array}$ \\
\hline \multicolumn{3}{|l|}{ Studies included in the narrative review } \\
\hline $\begin{array}{l}\text { Malagoli et al. [37] } \\
\text { (medicated ED group) }\end{array}$ & $\begin{array}{l}\text { Tseng et al. [36] } \\
\text { (ED group with comorbid psychiatric disorders) }\end{array}$ & $\begin{array}{l}\text { Harper et al. [35] } \\
\text { (pre-and post-recovered AN) }\end{array}$ \\
\hline \multirow[t]{2}{*}{$\begin{array}{l}\text { Cholet et al. [33] } \\
\text { (AN-R only) }\end{array}$} & $\begin{array}{l}\text { Cavalera et al. [38] } \\
\text { (ED group not compared to HC) }\end{array}$ & \\
\hline & $\begin{array}{l}\text { Ogata et al. [34] } \\
\text { (AN-R only) }\end{array}$ & \\
\hline
\end{tabular}

Anorexia nervosa (AN), eating disorders (ED), healthy controls (HC), restricting subtype of anorexia nervosa (AN-R)

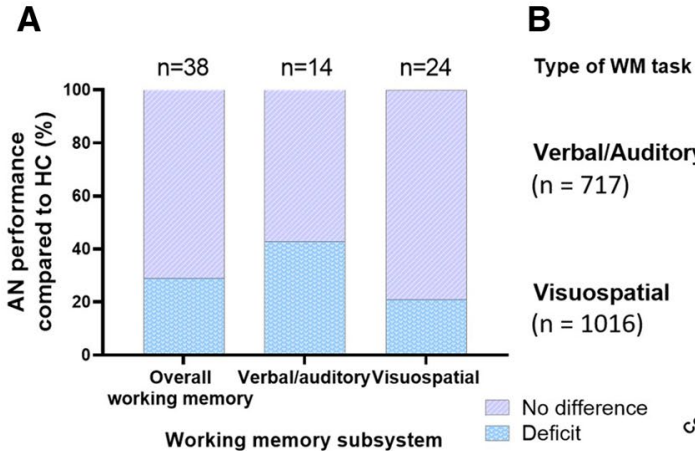

Fig. 2 A Working memory (WM) performance in the anorexia nervosa (AN) group compared to the healthy control (HC) group in all WM tasks, verbal/auditory and visuospatial WM tasks, respectively. B AN performance in specific WM tasks, compared to HC. The total sample size in the verbal/auditory domain was 717 participants, and for the visuospatial domain the total sample size was 1016 partici- pants. The annotated $n$ indicates the number of WM tasks used in the reviewed studies. Letter Number Sequencing (LNS), Rey Auditory Verbal Learning Test (RAVLT), Verbal Learning and Memory Test (VLMT), Rey Complex Figure Test (RCFT), Symbol-Digit Modalities Test (SDMT), Trail Making Test (TMT-B)-part B did not differ in the RCFT, and were not compared to a HC group. Across the reviewed studies directly comparing AN and HC samples, AN participants were impaired in $20.8 \%$ of the visuospatial WM tasks but showed normal WM capacity in $79.2 \%$ (Fig. 2A).

\section{Differential WM performance according to age groups}

Out of the reviewed studies, one investigated early-onset AN (EO-AN) in children (9-14 years), six tested adolescents (11.5-19 years), thirteen tested adults ( $>18$ years) and seven studies used a mixed participant group with both adolescents and adults (Table 1). 


\section{Children with EO-AN}

EO-AN childern did not differ from age-matched $\mathrm{HC}$ in visuospatial WM abilities measured in the RCFT and TMT [39]. Nor did the children with EO-AN and adolescents with AN differ in the TMT, while healthy adolescents were significantly better than healthy children in the sample [39].

\section{Adolescents with AN}

Were also found to have deficits in the visuospatial TMT [73]. The remaining $86 \%$ of the studies using visuospatial digit span, RCFT and TMT in adolescent AN did not reveal statistically significant differences, as illustrated in Fig. 3A [39, 41, 74]. Zegarra-Valdivia and Chino-Vilca (2018) were the only research group to report an inferior verbal/auditory WM performance in adolescent AN participants completing the verbal digit span task (Online Resource Table S3) [43].

\section{Adult individuals with AN}

Performed worse than $\mathrm{HC}$ in $44.4 \%$ of the verbal/auditory tasks [59-61], while no difference was found in 55.6\% [42, 55, 57, 58] (Fig. 3B). The findings in the visuospatial WM domain showed no prominent differences between the AN and $\mathrm{HC}$ cohorts in $85.7 \%$ of tasks $[57,61,72,75]$, while the AN group was worse than the $\mathrm{HC}$ in the remaining $14.3 \%$ [58].

\section{Studies with a combination of adolescents and adults}

No WM component differences were found at the group level when age groups of AN cohorts were mixed in studies. The reviewed studies presented WM impairments in approximately $25 \%$ of the tasks relying on the phonological loop and in 30\% using the visuospatial sketchpad [56, 76] (Fig. 3C). No statistically significant differences emerged between mixed-age $\mathrm{AN}$ and $\mathrm{HC}$ in $75 \%$ of the verbal/auditory WM tasks $[40,56,62]$ or in $70 \%$ of the visuospatial WM tests [40, 56, 62, 71] (Fig. 3C).

\section{WM in the subtypes of anorexia}

Patient subtype specifications were collected from sixteen of the reviewed publications, giving a total $n=428$ for AN-R and $n=163$ for AN-BP. The reviewed studies gave mixed accounts regarding potential subtype-specific changes in WM capacity, presented in more detail below.

\section{Restricting AN patients}

in the mixed adolescent and adult group of Natalia et al. [56] presented with significantly impaired performance in the verbal/auditory VLMT, and the visuospatial backward Corsi Blocks, SDMT and in the reaction time of the 2-back test [56]. Interestingly, AN-R did not deviate from the $\mathrm{HC}$ in forward Corsi Blocks, digit span, 3-back or the RCFT. Nor did the adult and mixed adolescent and adult groups of AN-R patients show altered WM functioning in the verbal/auditory digit span and LNS in comparison to $\mathrm{HC}[33,34,55,62]$ or in the visuospatial spatial span [62]. However, adolescents and adults with AN-R combined had a significantly faster recall time than the control group for the visuospatial RCFT [33]. This was an outlier study responsible for the superior AN-related performance in 4\% of the visuospatial WM tasks (Fig. 4, Online Resource Table S4). The recent publication by Rylander et al. (2020) investigated cognitive functioning in patients with severe AN pre- and post-medical stabilisation [72]. Severe AN was defined as weighing less than 70\% of the ideal body weight (IBW), calculated using patient

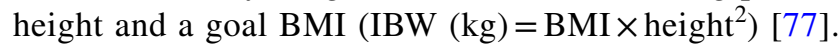
Neither AN-R nor AN-BP patients differed from the nonED control group in baseline visuospatial TMT results. After
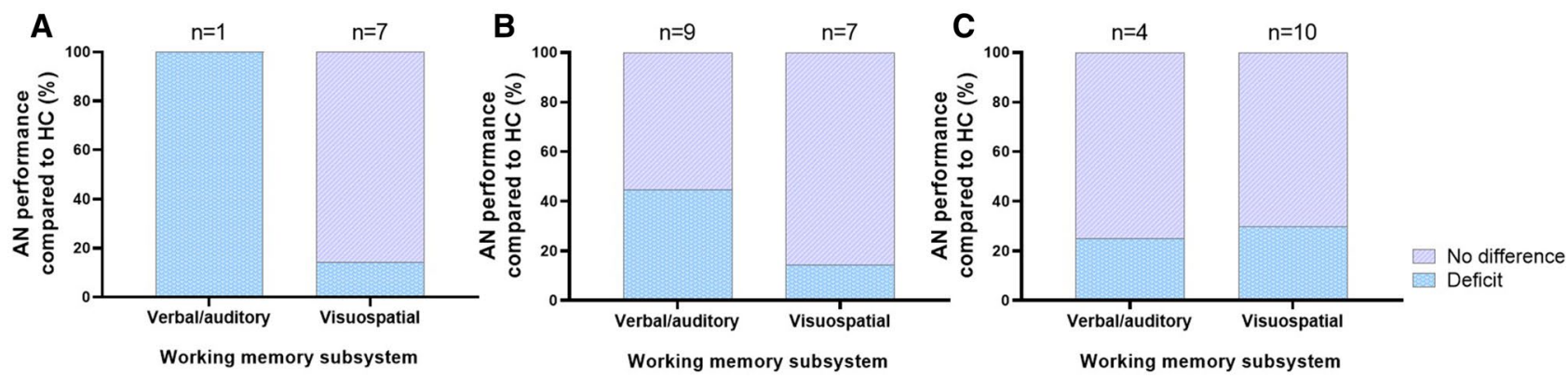

Fig. 3 Working memory (WM) performance in adolescent (A), adult (B) and mixed aged (C) anorexia nervosa (AN) groups compared to ospatial WM tasks. The annotated $n$ indicates the number of WM tasks used in the reviewed studies 
three weeks of refeeding and improved organ and oedema status, AN-R displayed significant improvements in TMT scores while the AN-BP patients did not.

\section{Binge/purging AN patients}

were argued by Tamiya et al. [62] to have more widespread cognitive dysfunctions, but this was not evident in the WM measures [62]. Individuals with AN-BP performed at the same level as HC in the verbal/auditory digit span and LNS, as well as the visuospatial spatial span [55, 62]. The small AN-BP sample sizes were insufficient to perform additional statistical analysis in Natalia et al. [56] and Terhoeven et al. [58].

\section{Psychiatric comorbidities among the AN participants}

In order of prevalence, the following comorbidities were reported: depression [36, 40, 55], anxiety [33, 40, 41, 55], affective disorder [18, 33], suicide risk [33], stress-related disorders, mood disorder, personality disorder [42], bipolar disorder [36], addictive behaviours, attention deficit hyperactivity disorder [33], autism spectrum disorder and psychotic symptoms [18] (Table 1). Obsessive compulsive disorder (OCD) was also present in the patient cohorts of van Noort et al. [39] and Malagoli et al. [37], but no exact demographic values were given and no links between WM performance and OCD were made despite the high comorbidity risk in AN, and in particular AN-BP [78, 79]. Twelve of the studies included in this review outlined certain psychiatric co-morbidities and psychotropic medications as exclusion factors in AN patient recruitment [34, 55, 57-62, 72-74, 76].

In Tseng et al. [36] mixed ED group (AN, BN, BED, and Eating Disorder Not Otherwise Specified (EDNOS)), the participants with comorbid major depressive disorder (MDD) and bipolar I or II disorder were significantly worse in verbal/auditory arithmetic and digit span tasks, than ED patients with just MDD. Moreover, co-occurring bipolar I disorder was associated with overall impairments in WM and intelligence measures. Although the patients with AN in Konstantakopoulos et al. [60] lacked a comorbid psychiatric diagnosis, they found that those suffering from intense body image delusions performed significantly worse than the nondelusional patients in the verbal/auditory digit span task.

\section{Psychotropic medications used in the AN sample}

Eight of the reviewed publications included information on psychotropic medication use in AN participants of both subtypes [33, 36, 37, 41, 60-62, 73] (Table 1). Medications included antidepressants (e.g., selective serotonin reuptake

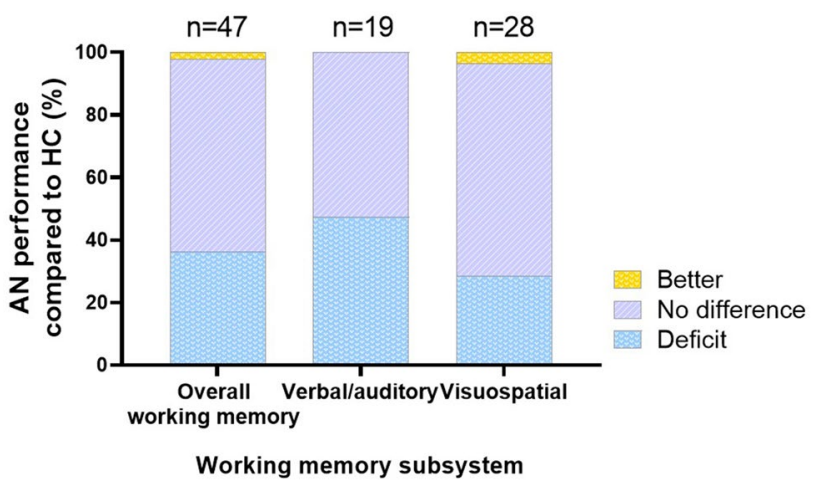

Fig. 4 Working memory (WM) performance in the full anorexia nervosa (AN) group, with and without reported AN subtypes, psychiatric comorbidities and medications, compared to the healthy control (HC) group in all WM tasks, verbal/auditory and visuospatial WM tasks, respectively. The annotated $n$ indicates the number of WM tasks used in the reviewed studies

inhibitors), anxiolytics, antipsychotics/neuroleptics and benzodiazepines. Medicated and unmedicated participants in Terhoeven et al. [61] did not differ regarding WM capacity. Conversely, Malagoli et al. [37] showed that a combined use of antidepressants and antipsychotics was related to significantly lower scores in the verbal/auditory RSPAN and visuospatial SymmSpan. When psychiatric comorbidities, medications and AN-R-specific data were visualised together with above AN versus $\mathrm{HC}$ results, AN-related deficits in occurred in $47.4 \%$ of the phonological tasks (Fig. 4). Taking the comorbidities, psychotropics and AN-R results into account also diminished the percentage of unaffected performance in visuospatial WM tasks from 79.2 to $67.9 \%$, while AN-related visuospatial deficits increased from 20.8 to $28.6 \%$ (Fig. 4 ).

\section{Discussion}

Earlier reviews on WM functioning in AN have provided various perspectives, ranging from impaired [80], enhanced [14], unaffected [81] to overall inconsistencies [26]. Progressing previous work solely focusing on WM in general, this current review presents novel findings that WM deficits associated with the phonological loop occur in $44 \%$ of tasks examining adults with AN versus healthy controls (HC), as opposed to only $14 \%$ of tasks relying on the visuospatial sketchpad. This phonological loop deficit was also observed in $47 \%$ of studies of AN adults when considering the restricting subtype, psychotropic medication and comorbidities combined. However, when examining mixed adolescent and adult groups, or considering both phonological and visuospatial WM tasks together, no deficits emerge in the AN literature published between 2016 and 2021. Against 
these new observations, the following sections will discuss in more detail how WM performance may contribute to core symptoms in $\mathrm{AN}$, and the potential implications phonological deficits may have for therapeutic treatment strategies.

\section{The phonological loop and visuospatial sketchpad are differentially affected in AN}

The well-established WM model postulates a division between phonological and visuospatial processing [15], highlighting a need to consider these specific domains separately in AN which has not been met in previous reviews $[14,26,80-82]$. Of the seven studies which included both verbal/auditory and visuospatial tasks, four of them did not detect a significant difference between $\mathrm{AN}$ and $\mathrm{HC}$ groups in either domain (a combined sample size of 266) (Table 3) [40, 42, 57, 62]. In the other three studies (a combined sample size of 165), there were mixed reports of verbal/auditory WM deficits [61], visuospatial WM deficits [58], and deficits in both WM domains for AN participants compared to HC [56]. By dividing the extracted WM tasks into those that measured verbal/auditory versus visuospatial domains, from all case versus control studies with a total sample size of 1302 participants, it was revealed that the AN group may experience greater difficulties in the verbal/auditory rather than the visuospatial aspects of WM where performance appears largely intact (Fig. 2A).

Similar findings have been reported by Biezonski et al. [83], where patients with AN were disadvantaged in the verbal/auditory LNS task but not the visuospatial TMT, in comparison to HC. Conversely, Lao-Kaim et al. [84] argue that patients with AN use the same cognitive strategies as $\mathrm{HC}$ to solve verbal WM tasks, but that visuospatial WM is dysfunctional [80]. A compromised visuospatial sketchpad may be due to intense weight fixation and other body dysmorphic obsessions [20]. Nevertheless, the 24 experiments across seven different visuospatial WM tasks examined in this review do not support inefficient visuospatial WM processing as a cognitive hallmark of $\mathrm{AN}$, as the patient groups did not significantly deviate from the $\mathrm{HC}$ even in the review's more recurring tasks, such as the Corsi Blocks and the TMT (Fig. 2, Online Resource Table S4). In comparison to the visuospatial domain, the verbal/auditory component of WM was understudied in the recent publications, with only 14 experiments across six different verbal/auditory WM tasks comparing a total of $717 \mathrm{AN}$ and $\mathrm{HC}$ participants. Despite the overall smaller sample size, in comparison to the 1016 participants tested in visuospatial WM tasks, an intriguing trend of phonological deficits emerged for adult AN patients versus $\mathrm{HC}$ in $44 \%$ of tasks (Fig. 3B).

As previously mentioned, the phonological loop is reliant on internal speech-mediated rehearsal [17]. Inhibiting rehearsal, e.g., through articulatory suppression by vocalising irrelevant words, may negatively impact WM performance [85]. Buchsbaum [86] stresses the importance of subvocal speech in a sense of self. The ability to hear and listen to this inner voice perceived to be one's own, assists in short-term recall but also with keeping internal mental representations active in WM. In line with this, AN has been described as a disorder of the self, where the anorexic inner voice is a key psychological component [24, 87, 88]. Indeed, the intrusive internal commentary on body shape, weight and eating has been associated with more harmful eating attitudes and restrictive or compensatory behaviours [24]. Thus, an inner voice preoccupied with AN-salient ruminations may impinge on non-AN-related rehearsal processes, perhaps comparable to articulatory suppression. In turn, the efficiency of verbal/auditory WM may be reduced, as indicated in the reviewed studies (Online Resource Table S3). Inefficient $\mathrm{WM}$ phonological rehearsal and updating may also be implicated in the cognitive and behavioural rigidities in AN and may contribute to its self-perpetuating nature [88].

\section{Testing adolescents and adults with AN separately reveals WM deficits}

The neural circuitry in fronto-striatal and parietal regions associated with WM undergoes a substantial maturation throughout adolescence and well into adulthood [89-91]. As AN typically has an adolescent onset, it is of interest to examine how neural development of cognitive control is affected in different age groups of AN patients. The Children with EO-AN did not differ from their healthy counterparts in visuospatial WM, but nor was an expected age-related improvement detected between EO-AN and adolescent AN groups [39]. Children tend to make more errors in WM maintenance and manipulation than adolescents and adults [92]. This has been attributed to a failure to recruit the dorsolateral prefrontal cortex (dlPFC) and superior parietal cortex, which are increasingly engaged with age, as WM processes become more refined [91]. The lack of age-related improvement in van Noort et al. (2016) may be due to the cross-sectional design of the study rather than a longitudinal, but it could also indicate a cognitive disruption during a critical developmental period.

Separate adolescent and adult AN age groups showed similar trends of a largely preserved visuospatial WM. Adolescents with AN were described to have an inferior verbal digit span performance [43], which is in accordance with earlier reports of limited short-term verbal memory in adolescent AN [18]. However, additional reports of verbal/ auditory WM in adolescents were lacking, which prevents further theories regarding differentially affected WM subsystems in adolescent AN. Curiously, the adults with AN were more likely to underperform compared to $\mathrm{HC}$ in tasks 
examining the phonological loop, e.g. RAVLT/VLMT and story recall, than in visuospatial measures [61]. This presents the possibility of a subtype-specific WM deficit in adult AN (Fig. 3B). Although an age-related maturation of fronto-parietal structures is not the sole driver of WM development, adult WM deficits are a cause for concern [90]. With age comes the ability to integrate additional executive networks, e.g., inhibitory control, and deactivate non-executive regions, e.g., the default network, which are critical during high WM loads [93, 94]. With a longer illness duration and accompanying malnutrition, more severe long-term effects on the brain and cognition are anticipated $[82,95,96]$. Regardless, there is a lack of consensus of the impact of illness duration on WM function in the reviewed literature. Zegarra-Valdivia and Chino-Vilca [43] highlighted a significant correlation between illness duration and poorer WM performance, while Tamiya et al. [62] and Malagoli et al. [37] did not find evidence for this. Alternatively, the plasticity of the adolescent brain could be concealing ANinduced difficulties with WM, while the less plastic adult brain may fail to compensate for these alterations and gives rise to more prominent deficits $[89,91]$.

Patient cohorts with both adolescents and adults demonstrated intact WM functioning in $71 \%$ and impaired performance in $29 \%$ of all tasks, consistent with Reville et al. [81] review and the claims of a preserved general WM capacity even in the chronically starved state of AN [84, 97]. Unlike what became evident in the separate adolescent and adult groups, distinguishing between the verbal/auditory and visuospatial tasks did not unveil AN-related deficits in either domain (Fig. 3C). What becomes clear from examining the distinct age groups in the reviewed literature, is that separating adolescents and adults could be a prerequisite for disentangling AN-related alterations in WM. Thus, future studies could examine age ranges that reflect different stages of development to determine the influence of neuronal development differences and duration of illness on WM performance.

\section{How does WM differ in subtypes of AN?}

According to the impulse control spectrum model of EDs, individuals with AN-R have a higher degree of cognitive restriction compared to those with AN-BP who engage in binge-eating and weight-compensatory behaviours [7, 26]. On the other hand, patients with AN-BP have been shown to be more perfectionistic than those diagnosed with AN-R [98]. Against this background, the reviewed publications were examined for subtype-specific alterations in WM. The restricting subtype was found to be more commonly studied than binge-purge AN in the combined sample. Cholet et al. [33] proposed that the AN-R classification is further divided into two profiles, (1) more extensive cognitive impairment and milder psychopathological symptoms and (2) symptoms of depression and anxiety and less affected in the cognitive domain. Surprisingly, it was the first subgroup that outperformed $\mathrm{HC}$ in visuospatial RCFT recall time which was the only account of an enhanced WM capacity in the reviewed publications [33]. Advantages in RCFT and higher accuracy in the n-back task have been previously reported for AN-R cohorts $[13,18]$. However, an elevated performance did not apply to the visuospatial TMT or spatial span WM measures [18]. Thus, deviating WM performances in AN-R may be highly task-dependent.

As previously mentioned in the introduction, an individual's subtype is not static and may change over the course of illness $[9,10]$. Often those diagnosed with AN-R move towards the more impulsive pole of the spectrum model, and into the AN-BP category following treatment $[7,9,99]$. While Tamiya et al. [62] reasoned that the AN-BP subtype had more extensive cognitive dysfunctions in processing speed, attention and problem-solving, Rylander et al. [72] discussed that AN-BP patients might be spared from the chronic nutritional deprivation in AN-R. Still, the relationship between malnutrition, BMI and cognition is complex and requires further investigation [62, 72]. The high degree of cross-over between subtypes also poses the question if they should be considered phases rather than separate categories and should be evaluated in future research $[9,100$, 101].

\section{Comorbidities and medications are confounding factors in the reviewed studies}

Psychiatric comorbidities are common in EDs [5] and WM deficits are considered general features of psychotic and affective disorders [102-104]. Comorbid participant samples are indisputably more representative of ED patients, but the intertwined psychopathology patterns make it difficult to unveil disorder-specific WM changes. Therefore, this review examined the occurrence of comorbidity in the tested AN groups. The most prevalent comorbidities were depression and anxiety. This is consistent with the risk loci for major depressive disorder (MDD) and anxiety identified in an extensive genome-wide association study (GWAS) based on 16,992 AN cases [78]. While both psychiatric disorders have been described as disruptive for WM, anxiety may specifically exacerbate EF deficits in EDs [102, 103, 105].

None of reviewed studies propose anxiety as an aggravating factor in AN-related WM impairments. Instead, Tseng et al. [36] presented manic-depressive bipolar I disorder as having adverse effects on WM when co-occurring with EDs and MDD. Although clear associations between bipolar disorder and BN have been made, the relationship with AN is more obscure [106, 107]. Nevertheless, comorbid bipolar and eating disorders may result in an earlier onset and more 
rapid changes between manic/hypomanic and depressive states [108]. The increased propensity of WM deficits in the more severe subtype bipolar I disorder noted by Tseng et al. [36], may be prompted by white matter abnormalities affecting the dorsal cognitive control system, while white matter abnormalities in hypomanic-depressive bipolar II disorder are more prominent in areas relevant to ventral emotion processing $[109,110]$. Likewise, different EDs may have varying psychiatric risks which could be problematic for interpreting results from mixed ED cohorts, such as Tseng et al. [36], Cavalera et al. [38], and Malagoli et al. [37]. Like the aforementioned Harper et al. [35] study, Tseng et al. [36] did not incorporate HC into their methodology which limits the conclusions that can be drawn from these reviewed publications.

In the same manner that psychiatric comorbidities may influence WM performance, the medications taken to treat these may also cause aberrant WM processing, as demonstrated by the ED group receiving antidepressants and antipsychotics in Malagoli et al. [37]. Antidepressants, such as serotonergic reuptake inhibitors, improve WM in MDD patients while potentially having adverse WM effects in healthy subjects $[111,112]$. Furthermore, the antipsychotic risperidone has been found to cause long lasting WM impairments in schizophrenia patients [113]. Risperidone antagonises dopaminergic $\mathrm{D}_{2}$ and serotonergic 5- $\mathrm{HT}_{2 \mathrm{~A}}$ receptors, triggering a downregulation of $\mathrm{D}_{1}$ receptors and a reduction of 5- $\mathrm{HT}_{2 \mathrm{~A}}$-mediated dopamine release in the dIPFC $[114,115]$. While this mechanism of action is beneficial for reducing symptoms of schizophrenia, it may also disrupt dopaminergic signalling involved in WM, whereby both too high and too low levels in the PFC negatively affects performance [116]. Despite the well-established insights on how psychotropic medications alter cognitive processes, only a minority of the reviewed studies perform separate statistical analyses to address this issue. Together with the studies with mixed ED groups, comorbidities and without $\mathrm{HC}$, these limitations further impede conclusions on how AN specifically affects WM.

\section{Neural perspectives of the WM components in AN}

WM is broadly considered a top-down cognitive control process that acts in opposition to bottom-up appetite and salience networks $[117,118]$. However, neuroanatomical research is divided in attributing WM processing changes in AN to either excessive dorsal control or alterations in ventral dopaminergic signalling [19, 119-122]. Kaye et al. [26] argue that individuals with AN have a hyperactive top-down modulation which drives the mindset of forgo food now, become thinner later. Alternatively, excessive top-down control could be a reaction to a highjacked bottom-up reward circuitry where anorexigenic behaviours have gained reward salience in a manner resembling addiction [123-125]. As the insula acts as a pivoting point between these two neural processing paths (PFC in top-down and striatum in bottom-up), Nunn et al. [126] offer an additional hypothesis of a rate-limiting dysfunction creating an imbalance between cognition and interoception in the anorectic brain.

In light of the current review's findings, it is of particular interest to disentangle how the neural pathways of the phonological loop and visuospatial sketchpad are influenced in AN. Verbal/auditory tasks recruit language production and comprehension regions, such as Broca's area in the frontal lobe, Wernike's area in the temporal lobe and the supra-marginal gyrus [127]. Visuospatial WM involves a widespread activation of the right-lateralised dIPFC, anterior cingulate, superior temporal gyrus, interoccipital sulcus, basal ganglia and the bilateral anterior insula [128]. To investigate potential differences between verbal and visuospatial WM processes on a neural level in AN, the n-back task would be highly suitable, as it can be modified to an auditory or a visual version, and thus allow differentiation between WM components within patients [29]. Lycke et al. [129] coupled this approach with functional magnetic resonance imaging (fMRI) in a healthy sample. Interestingly, the phonological n-back elicited a left-lateralised activation, while also recruiting the frontal cortex to a greater extent than the visuospatial n-back [129]. As AN patients have been suggested to have a reduced resting-state functional connectivity of the inferior frontal gyrus, the location of Broca's area, they may be less able to employ this region for phonological WM tasks [130].

Moreover, neural activity patterns underlying inner speech in WM have been explored by instructing participants to silently rehearse alphabetical letters [131]. In contrast to the storage condition, the manipulation of information using inner speech increased neural activity in the inferior frontal cortex and the cerebellum [131]. What further adds to the complexity of internalised vocalisation, is that monologic and dialogic inner speech may elicit different activity patterns, as seen in participants asked to generate internal self-talk in response to scenarios during fMRI [132]. A difference between monologic and dialogic inner speech may be of importance in $\mathrm{AN}$, as the anorexic voice could be experienced as second- or third-person commentary [23]. Similar research in AN patients is lacking, but prospective studies could offer neuroanatomical insights into the anorexic voice and potential overlaps with WM processes.

\section{Future directions and implications}

The difficulties in neuropsychological functioning that may arise in AN are becoming increasingly characterised (e.g. [133]). Inevitably, this has prompted re-evaluation of 
treatments, such as family therapy for adolescents and cognitive behavioural therapy for adults, which are cognitively demanding [134]. To bridge the gap between readiness-fortreatment and treatment itself, Davies and Tchanturia [134] adapted cognitive strategies used to alter thinking processes in psychiatric disorders to create an AN-focused cognitive remediation therapy (CRT). The overall goal of CRT is to enhance awareness of rigid cognitions, independently of EDrelated cognitions, which in turn benefit the participation in primary therapies [136]. Although CRT for AN targets set shifting and central coherence deficits, there is support for the targeting of WM as well within such therapies [73, 137, 138], particularly according to this review, within the phonological (verbal/auditory) domain. Likewise, WM may be targeted in attention bias modification training aiming to re-evaluate AN-salient stimuli such as food [138]. Changing how attention is allocated in AN, could prevent the updating of pathological ruminations held in WM and allow new associations, e.g., viewing food without fear, to be rehearsed [138].

The findings of the current review invite experimental approaches to test whether phonological WM is indeed impaired in AN. For example, dual tasking has been successful in reducing the emotionality of auditory hallucinations [140]. By manipulating the active conditions, e.g., auditory taxation (counting aloud) or visual taxation (eye movements) while performing a task, the methodology could help with pinpointing any modality-specific deficits in AN cohorts. If an anorexic voice acts as hijacker of the phonological loop, future intervention strategies could involve firstly acknowledging the repetitive critical commentary and then work to restructure the maladaptive tone of the voice [22, 141]. However, the inherent subvocal nature of this proposed phenomena makes it difficult to systematically capture [86]. An initial step in resolving this could be through the recently developed Experience of an Anorexic VoicE Questionnaire (EAVE-Q) [142]. Although the early validity and internal consistency measures of the EAVE-Q have been promising, further re-tests will be necessary to fully determine its reliability. Moreover, it would be intriguing to examine the relationship between verbal/auditory WM performance and EAVE-Q scores before and after a period of exercises aimed to enhance the phonological loop and treat disorder-related inner speech.

\section{Strength and limits}

This systematic review emphasises that there are still elements of WM capacity that need further consideration in the context the development and maintenance of AN. Importantly, we stress that modality-specific approaches when measuring WM in AN are needed, rather than combining phonological and visuospatial results. We also considered the separate age groups of patients in the reviewed papers, which revealed that deficits in WM may go undetected when adolescents and adults with AN are grouped together. The number of verbal/auditory WM tasks was underpowered in the reviewed publications, which limits the conclusions that can be drawn and justifies further experimental attention on the nature of WM in AN. Interestingly, the auditory n-back was not used in any of the reviewed studies despite being a standard WM measure [143, 144]. We must also consider that neuropsychological tests often assess several domains of executive functioning, which is why we must be cautious about the specificity of the detected impairments [145]. The review did not include intelligent quotient (IQ) as an outcome measure, as nine of the studies included in the main analysis did not detect a statistical significant difference between the AN and HC groups [40, 55, 56, 59, 60, 62, 72, 75, 76] (Online Resource Table S5). Six of the studies did not use an IQ measure [42, 43, 57, 71, 73, 74], three studies IQ-matched $\mathrm{HC}$ and AN patients [39, 58, 61], while only one found differences in verbal and non-verbal IQ in AN patients [18]. However, IQ has been suggested to be above average in individuals with AN and is closely related to WM, which makes it an outcome of interest for this research area [146, 147]. In addition, incorporating fMRI techniques during WM task performance (e.g. [129, 131]) would provide further insights into the active brain regions and underlying neural mechanisms than underpin EDs. Another concern is that some of the reviewed studies did not report or control for medication use and psychiatric comorbidities. As $70 \%$ of individuals with an ED are also burdened by comorbidities, the confounding effects of other disorders and pharmacological treatments against these, e.g., antidepressants and antipsychotics, need to be examined as well [148]. Furthermore, the majority of the included studies had all-female participant groups, which limits the generalizability of our findings to the male population.

\section{Conclusion}

This study is, to our knowledge, the first to review verbal/ auditory and visuospatial WM as separate domains in individuals with AN. When WM is examined globally in mixed ages of AN patients, only a minority of studies exhibit deficits. However, when adolescents and adults are tested separately in each of the two WM subsystems, it appears that the phonological domain is selectively impaired. This could be the consequence of an anorexic voice disturbing rehearsal processes essential for a healthier, non-ED lifestyle. Thus, the novel findings of this systematic review emphasise that $\mathrm{WM}$ as a cognitive marker for AN should not be overlooked. Instead, future research would benefit from distinguishing the WM subsystems and addressing the complex interplay 
between AN subtypes, duration of illness and accompanying comorbidities.

\section{What is already known on this subject?}

Research is divided regarding if working memory is influenced in anorexia. Cognitive deficits are becoming increasingly characterised, but the high frequency of comorbidities makes this challenging.

\section{What does this study add?}

The results indicated that analysing working memory subsystems and age groups separately, should be considered prerequisites for disentangling anorexia-related alterations in working memory.

Supplementary Information The online version contains supplementary material available at https://doi.org/10.1007/s40519-022-01370-1.

Acknowledgments H.B.S. is supported by the Swedish Research Council and the Swedish Brain Foundation. The Swedish Research Foundation and the Swedish Brain Foundation had no role in the study design, collection, analysis or interpretation of the data, writing the manuscript, or the decision to submit the paper for publication.

Author contributions All authors contributed to the study conception and design. Material preparation, data collection and analysis were performed by ADD, SG, and SJB. Resources were provided by HBS. The first draft of the manuscript was written by ADD and all authors commented on previous versions of the manuscript. All authors read and approved the final manuscript.

Funding Open access funding provided by Uppsala University. H.B.S. is supported by the Swedish Research Council and the Swedish Brain Foundation. This study was funded by Vetenskapsrådet and Hjärnfonden.

\section{Declarations}

Conflict of interest Santino Gaudio is a guest editor of Eating and Weight Disorders.

Informed consent For this type of study, consent is not required.

Open Access This article is licensed under a Creative Commons Attribution 4.0 International License, which permits use, sharing, adaptation, distribution and reproduction in any medium or format, as long as you give appropriate credit to the original author(s) and the source, provide a link to the Creative Commons licence, and indicate if changes were made. The images or other third party material in this article are included in the article's Creative Commons licence, unless indicated otherwise in a credit line to the material. If material is not included in the article's Creative Commons licence and your intended use is not permitted by statutory regulation or exceeds the permitted use, you will need to obtain permission directly from the copyright holder. To view a copy of this licence, visit http://creativecommons.org/licenses/by/4.0/.

\section{References}

1. American Psychiatric Association. (2013). Diagnostic and statistical manual of mental disorders (5th ed.). Arlington, VA
2. Stunkard AJ, Messick SM (1985) The three-factor eating questionnaire to measure dietary restraint, disinhibition and hunger. J Psychosom Res 29(1):71-83. https://doi.org/10.1016/00223999(85)90010-8

3. Wentz E, Gillberg IC, Anckarsäter H, Gillberg C, Råstam M (2009) Adolescent-onset anorexia nervosa: 18-year outcome. Br J Psychiatry 194(2):168-174. https://doi.org/10.1192/bjp.bp.107. 048686

4. Fichter MM, Quadflieg N, Crosby RD, Koch S (2017) Longterm outcome of anorexia nervosa: results from a large clinical longitudinal study. Int J Eat Disord 50(9):1018-1030. https://doi. org/10.1002/eat.22736

5. Van Alsten SC, Duncan AE (2020) Lifetime patterns of comorbidity in eating disorders: an approach using sequence analysis. Eur Eat Disord Rev 28(6):709-723. https://doi.org/10.1002/erv. 2767

6. Smink FR, van Hoeken D, Hoek HW (2013) Epidemiology, course, and outcome of eating disorders. Curr Opin Psychiatry 26(6):543-548. https://doi.org/10.1097/YCO.0b013e328365a24f

7. Brooks SJ, Rask-Andersen M, Benedict C, Schiöth HB (2012) A debate on current eating disorder diagnoses in light of neurobiological findings: is it time for a spectrum model? BMC Psychiatry 12(1):76. https://doi.org/10.1186/1471-244X-12-76

8. Solstrand Dahlberg L, Wiemerslage L, Swenne I, Larsen A, Stark J, Rask-Andersen M, Salonen-Ros H, Larsson EM, Schiöth HB, Brooks SJ (2017) Adolescents newly diagnosed with eating disorders have structural differences in brain regions linked with eating disorder symptoms. Nord J Psychiatry 71(3):188-196. https://doi.org/10.1080/08039488.2016. 1250948

9. Eddy KT, Keel PK, Dorer DJ, Delinsky SS, Franko DL, Herzog DB (2002) Longitudinal comparison of anorexia nervosa subtypes. Int J Eat Disord 31(2):191-201. https://doi.org/10. 1002/eat. 10016

10. Fairburn CG, Cooper Z, Shafran R (2003) Cognitive behaviour therapy for eating disorders: a "transdiagnostic" theory and treatment. Behav Res Ther 41(5):509-528. https://doi.org/10. 1016/S0005-7967(02)00088-8

11. Dickson H, Brooks S, Uher R, Tchanturia K, Treasure J, Campbell IC (2008) The inability to ignore: distractibility in women with restricting anorexia nervosa. Psychol Med 38(12):17411748. https://doi.org/10.1017/S0033291708002961

12. Hatch A, Madden S, Kohn MR, Clarke S, Touyz S, Gordon E, Williams LM (2010) In first presentation adolescent anorexia nervosa, do cognitive markers of underweight status change with weight gain following a refeeding intervention? Int J Eat Disord 43(4):295-306. https://doi.org/10.1002/eat.20695

13. Brooks SJ, O'Daly OG, Uher R, Schiöth HB, Treasure J, Campbell IC (2012) Subliminal food images compromise superior working memory performance in women with restricting anorexia nervosa. Conscious Cogn 21(2):751-763. https://doi. org/10.1016/j.concog.2012.02.006

14. Brooks SJ (2016) A debate on working memory and cognitive control: can we learn about the treatment of substance use disorders from the neural correlates of anorexia nervosa? BMC Psychiatry 16(1):10. https://doi.org/10.1186/ s12888-016-0714-z

15. Baddeley AD, Hitch G (1974) Working memory. In: Psychology of Learning and Motivation, Vol. 8,. Academic press, Cambridge, pp 47-89. https://doi.org/10.1016/S0079-7421(08)60452-1

16. Diamond A (2013) Executive functions. Annu Rev Psychol 64:135-168. https://doi.org/10.1146/annur ev-psych-113011-143750

17. Salamé P, Baddeley A (1982) Disruption of short-term memory by unattended speech: implications for the structure of working 
memory. J Verbal Learn Verbal Behav 21(2):150-164. https:// doi.org/10.1016/S0022-5371(82)90521-7

18. Kjærsdam Telléus G, Jepsen JR, Bentz M, Christiansen E, Jensen SO, Fagerlund B, Thomsen PH (2015) Cognitive profile of children and adolescents with anorexia nervosa. Eur Eat Disord Rev 23(1):34-42. https://doi.org/10.1002/erv.2337

19. Startup H, Lavender A, Oldershaw A, Stott R, Tchanturia K, Treasure J, Schmidt U (2013) Worry and rumination in anorexia nervosa. Behav Cog Psychother 41(3):301. https://doi.org/10. 1017/S1352465812000847

20. Kemps E, Tiggemann M, Wade T, Ben-Tovim D, Breyer R (2006) Selective working memory deficits in anorexia nervosa. Eur Eat Disord Rev 14(2):97-103. https://doi.org/10.1002/erv.685

21. Bruch H (1978) The golden cage: the enigma of anorexia nervosa. Harvard University Press, Cambridge

22. Tierney S, Fox JR (2010) Living with the anorexic voice: a thematic analysis. Psychol Psychother 83(3):243-254. https://doi. org/10.1348/147608309X480172

23. Pugh M (2016) The internal 'anorexic voice': a feature or fallacy of eating disorders? Adv Eat Disord 4(1):75-83. https://doi.org/ $10.1080 / 21662630.2015 .1116017$

24. Pugh M, Waller G (2017) Understanding the 'anorexic voice' in anorexia nervosa. Clin Psychol Psychother 24(3):670-676. https://doi.org/10.1002/cpp.2034

25. Noordenbos G, van Geest Z (2017) Self-criticism and critical voices in eating disorder patients and healthy controls. JSM Nutri Disord 1(1):1003-1008

26. Kaye WH, Fudge JL, Paulus M (2009) New insights into symptoms and neurocircuit function of anorexia nervosa. Nat Rev Neurosci 10(8):573-584. https://doi.org/10.1038/nrn2682

27. Brooks SJ, Funk SG, Young SY, Schiöth HB (2017) The role of working memory for cognitive control in anorexia nervosa versus substance use disorder. Front Psychol 8:1651. https:// doi.org/10.3389/fpsyg.2017.01651

28. Turner ML, Engle RW (1989) Is working memory capacity task dependent? J Mem Lang 28(2):127-154. https://doi.org/ 10.1016/0749-596X(89)90040-5

29. Chai WJ, Abd Hamid AI, Abdullah JM (2018) Working memory from the psychological and neurosciences perspectives: a review. Front Psychol 9:401. https://doi.org/10.3389/fpsyg. 2018.00401

30. Wang M, Gamo NJ, Yang Y, Jin LE, Wang XJ, Laubach M, Mazer JA, Lee D, Arnsten AF (2011) Neuronal basis of agerelated working memory decline. Nature 476(7359):210-213. https://doi.org/10.1038/nature10243

31. Moher D, Liberati A, Tetzlaff J, Altman DG, The PRISMA Group (2009) Preferred reporting items for systematic reviews and meta-analyses: the PRISMA statement. PLoS Med 6(7):e1000097. https://doi.org/10.1371/journal.pmed1000097

32. Downes MJ, Brennan ML, Williams HC, Dean RS (2016) Development of a critical appraisal tool to assess the quality of crosssectional studies (AXIS). BMJ Open 6(12):011458. https://doi. org/10.1136/bmjopen-2016-011458

33. Cholet J, Rousselet M, Donnio Y, Burlot M, Pere M, Lambert S, Rocher B, Chirio-Espitalier M, Eyzop E, Grall-Bronnec M (2021) Evaluation of cognitive impairment in a French sample of patients with restrictive anorexia nervosa: two distinct profiles emerged with differences in impaired functions and psychopathological symptoms. Eat Weight Disord 26:1559-1570. https://doi. org/10.1007/s40519-020-00981-w

34. Ogata K, Koyama KI, Fukumoto T, Kawazu S, Kawamoto M, Yamaguchi E, Fuku Y, Amitani M, Amitani H, Sagiyama KI, Inui A, Asakawa A (2021) The relationship between premorbid intelligence and symptoms of severe anorexia nervosa restricting type. Int J Med Sci 18(7):1566-1569. https://doi.org/10.7150/ ijms.53907
35. Harper J, Brodrick B, Van Enkevort E, McAdams C (2017) Neuropsychological and cognitive correlates of recovery in anorexia nervosa. Eur Eat Disord Rev 25(6):491-500. https://doi.org/10. 1002/erv. 2539

36. Tseng M, Chang C, Liao S, Chen H (2017) Comparison of associated features and drug treatment between co-occurring unipolar and bipolar disorders in depressed eating disorder patients. BMC Psychiatry. https://doi.org/10.1186/s12888-017-1243-0

37. Malagoli C, Cerro P, Vecchiato C, Usai M (2020) Cognitive and emotional regulation in adolescents and young women with eating disorders. Eat Weight Disord. https://doi.org/10.1007/ s40519-020-00859-x

38. Cavalera C, Pepe A, Zurloni V, Diana B, Realdon O, Todisco P, Castelnuovo G, Molinari E, Pagnini F (2018) Negative social emotions and cognition: Shame, guilt and working memory impairments. Acta Psychol 188:9-15. https://doi.org/10.1016/j. actpsy.2018.05.005

39. van Noort B, Pfeiffer E, Ehrlich S, Lehmkuhl U, Kappel V (2016) Cognitive performance in children with acute early-onset anorexia nervosa. Eur Child Adolesc Psychiatry 25(11):1233-1244. https://doi.org/10.1007/s00787-016-0847-0

40. Foerde K, Steinglass J (2017) Decreased feedback learning in anorexia nervosa persists after weight restoration. Int J Eat Disord 50(4):415-423. https://doi.org/10.1002/eat.22709

41. Kjærsdam Telléus G, Fagerlund B, Jepsen J, Bentz M, Christiansen E, Valentin J, Thomsen P (2016) Are Weight Status and Cognition Associated? An Examination of Cognitive Development in Children and Adolescents with Anorexia Nervosa 1 Year after First Hospitalisation. Eur Eat Disord Rev 24(5):366376. https://doi.org/10.1002/erv.2445

42. Seidel M, Brooker H, Lauenborg K, Wesnes K, Sjögren M (2021) Cognitive function in adults with enduring anorexia nervosa. Nutrients 13(3):859. https://doi.org/10.3390/nu130 30859

43. Zegarra-Valdivia J, Chino-Vilca B (2018) Social cognition and executive function impairment in young women with anorexia nervosa. Clín Salud 29(3):107-113. https://doi.org/10.5093/clysa 2018a1

44. Wechsler D (1981) Manual for the Wechsler adult intelligence scale-revised. The Psychological Corporation, New York

45. Wechsler D (1997) WAIS-III administration and scoring manual. The Psychological Corporation, San Antonio

46. Wechsler D (2008) WAIS-IV technical and interpretive manual. The Psychological Corporation, San Antonio

47. Wechsler D (1997) Wechsler Memory Scale-III. The Psychological Corporation, San Antonio

48. Rey A (1964) L'examen clinique en psychologie. Presses Universitaires \& France, Paris

49. Helmstaedter C, Durwen H (1990) VLMT: Verbaler Lern-und Merkfähigkeitstest: Ein praktikables und differenziertes Instrumentarium zur Prüfung der verbalen Gedächtnisleistungen. Schweizer Arch für Neurol und Psychiatr 141:21-30

50. Helmstaedter C, Lendt M, Lux S (2001) Verbaler Lern- und Merkfähigkeitstest (VLMT). Hogrefe, Göttingen

51. Daneman M, Carpenter PA (1980) Individual differences in working memory and reading. J Mem Lang 19(4):450. https:// doi.org/10.1016/S0022-5371(80)90312-6

52. Wechsler D (1987) Manual for the Wechsler memory scalerevised. The Psychological Corporation, San Antonio

53. Wesnes KA, Brooker H, Ballard C, McCambridge L, Stenton R, Corbett A (2017) Utility, reliability, sensitivity and validity of an online test system designed to monitor changes in cognitive function in clinical trials. Int J Geriatr Psychiatry 32(12):e83-e92. https://doi.org/10.1002/gps.4659

54. Lange RT (2011) Working Memory Index. In: Kreutzer JS, DeLuca J, Caplan B (eds) Encyclopedia of Clinical 
Neuropsychology. Springer, New York. https://doi.org/10.1007/ 978-0-387-79948-3_1076

55. Brockmeyer T, Anderle A, Schmidt H, Febry S, Wünsch-Leiteritz W, Leiteritz A, Friederich H (2018) Body image related negative interpretation bias in anorexia nervosa. Behav Res Ther 104:6973. https://doi.org/10.1016/j.brat.2018.03.003

56. Natalia A, Barbara R, Alain D, Klaus S, Klaus O, Peter W, Katharina $P$ (2017) Cognitive decline in patients with anorexia nervosa: which cognitive domains are most vulnerable and need to be considered? Exp Psychol Clin. https://doi.org/10.4172/ 2471-2701.1000162

57. Gagnon C, Bégin C, Laflamme V, Grondin S (2018) Temporal processing of joyful and disgusting food pictures by women with an eating disorder. Front Hum Neurosci. https://doi.org/10.3389/ fnhum.2018.00129

58. Terhoeven V, Nikendei C, Faschingbauer S, Huber J, Young KD, Bendszus M, Herzog W, Friederich H-C, Simon JJ (2021) Neurophysiological correlates of disorder-related autobiographical memory inanorexia nervosa. Psycholog Med. https://doi.org/10. 1017/S003329172100221X

59. Konstantakopoulos G, Ioannidi N, Patrikelis P, Gonidakis F (2020) Empathy, mentalizing, and cognitive functioning in anorexia nervosa and bulimia nervosa. Soc Neurosci 15(4):477-488. https://doi.org/10.1080/17470919.2020.1760131

60. Konstantakopoulos G, Ioannidi N, Patrikelis P, Gonidakis F (2020) The impact of theory of mind and neurocognition on delusionality in anorexia nervosa. J Clin Exp Neuropsychol 42(6):611-621. https://doi.org/10.1080/13803395.2020.1786504

61. Terhoeven V, Kallen U, Ingenerf K, Aschenbrenner S, Weisbrod M, Herzog W, Brockmeyer T, Friederich HC, Nikendei C (2017) Meaningful memory in acute anorexia nervosa patients-comparing recall, learning, and recognition of semantically related and semantically unrelated word stimuli. Eur Eat Disord Rev 25(2):89-97. https://doi.org/10.1002/erv.2496

62. Tamiya H, Ouchi A, Chen R, Miyazawa S, Akimoto Y, Kaneda Y, Sora I (2018) Neurocognitive impairments are more severe in the binge-eating/purging anorexia nervosa subtype than in the restricting subtype. Front Psychiatry. https://doi.org/10.3389/ fpsyt.2018.00138

63. Corsi PM (1972) Human memory and the medial temporal region of the brain [PhD thesis]. Montreal: McGill University, Montreal

64. Kirchner WK (1958) Age differences in short-term retention of rapidly changing information. J Exp Psychol 55(4):352. https:// doi.org/10.1037/h0043688

65. Rey A (1941) L'examen psychologique dans le cas d'encéphalopathie traumatique. Arch Psychol 28(112):286-340

66. Osterrieth PA (1944) Le test de copie d'une figure complexe: Contribution à l'étude de la perception et de la mémoire. Archives de Psychologie 30:286-356

67. Smith A (1973) Symbol digit modality test. Western Psychological Services, Los Angeles

68. Kane MJ, Hambrick DZ, Tuholski SW, Wilhelm O, Payne TW, Engle RW (2004) The generality of working memory capacity: a latent-variable approach to verbal and visuospatial memory span and reasoning. J Exp Psychol 133:189-217. https://doi.org/10. 1037/0096-3445.133.2.189

69. Armitage SG (1946) An analysis of certain psychological tests used for the evaluation of brain injury. Monogr Psychol. https:// doi.org/10.1037/h0093567

70. Reitan RM (1955) The relation of the trail making test to organic brain damage. J Consult Psychol 19(5):393. https://doi.org/10. 1037/h0044509

71. Cipolletta S, Malighetti C, Serino S, Riva G, Winter D (2017) Intrapersonal, interpersonal, and physical space in anorexia nervosa: a virtual reality and repertory grid investigation. Psychiatry Res 252:87-93. https://doi.org/10.1016/j.psychres.2017.02.060
72. Rylander M, Taylor G, Bennett S, Pierce C, Keniston A, Mehler $\mathrm{P}$ (2020) Evaluation of cognitive function in patients with severe anorexia nervosa before and after medical stabilization. J Eat Disord. https://doi.org/10.1186/s40337-020-00312-5

73. Kucharska K, Kulakowska D, Starzomska M, Rybakowski F, Biernacka K (2019) The improvement in neurocognitive functioning in anorexia nervosa adolescents throughout the integrative model of psychotherapy including cognitive remediation therapy. BMC Psychiatry. https://doi.org/10.1186/ s12888-018-1984-4

74. Vicario C, Felmingham K (2018) The perception of time is underestimated in adolescents with anorexia nervosa. Front Psychiatry. https://doi.org/10.3389/fpsyt.2018.00121

75. Øverås M, Kapstad H, Brunborg C, Landrø N, Rø Ø (2017) Is overestimation of body size associated with neuropsychological weaknesses in anorexia nervosa? Eur Eat Disord Rev 25(2):129134. https://doi.org/10.1002/erv.2500

76. Tenconi E, Collantoni E, Meregalli V, Bonello E, Zanetti T, Veronese A, Meneguzzo P, Favaro A (2021) Clinical and cognitive functioning changes after partial hospitalization in patients with anorexia nervosa. Front Psychiatry 12:653506. https://doi. org/10.3389/fpsyt.2021.653506

77. Peterson CM, Thomas DM, Blackburn GL, Heymsfield SB (2016) Universal equation for estimating ideal body weight and body weight at any BMI. Am J Clin Nutr 103(5):1197-1203. https://doi.org/10.3945/ajcn.115.121178

78. Watson HJ, Yilmaz Z, Thornton LM, Hübel C, Coleman JR, Gaspar HA, Bulik CM (2019) Genome-wide association study identifies eight risk loci and implicates metabo-psychiatric origins for anorexia nervosa. Nat Genet 51(8):1207-1214. https:// doi.org/10.1038/s41588-019-0439-2

79. Drakes DH, Fawcett EJ, Rose JP, Carter-Major JC, Fawcett JM (2021) Comorbid obsessive-compulsive disorder in individuals with eating disorders: an epidemiological meta-analysis. J Psychiatr Res 141:176-191. https://doi.org/10.1016/j.jpsychires. 2021.06.035

80. Zakzanis KK, Campbell Z, Polsinelli A (2010) Quantitative evidence for distinct cognitive impairment in anorexia nervosa and bulimia nervosa. J Neuropsychol 4(1):89-106. https://doi.org/10. 1348/174866409X459674

81. Reville MC, O'Connor L, Frampton I (2016) Literature review of cognitive neuroscience and anorexia nervosa. Curr Psychiatry Rep 18(2):18. https://doi.org/10.1007/s11920-015-0651-4

82. Stedal K, Broomfield C, Hay P, Touyz S, Scherer R (2021) Neuropsychological functioning in adult anorexia nervosa: a metaanalysis. Neurosci Biobehav Rev 130:214-226. https://doi.org/ 10.1016/j.neubiorev.2021.08.021

83. Biezonski D, Cha J, Steinglass J, Posner J (2016) Evidence for thalamocortical circuit abnormalities and associated cognitive dysfunctions in underweight individuals with anorexia nervosa. Neuropsychopharmacol 41(6):1560-1568. https://doi.org/10. 1038/npp.2015.314

84. Lao-Kaim NP, Giampietro VP, Williams SCR, Simmons A, Tchanturia K (2014) Functional MRI investigation of verbal working memory in adults with anorexia nervosa. Eur Psychiatry 29(4):211-218. https://doi.org/10.1016/j.eurpsy.2013.05.003

85. Baddeley A, Lewis V, Vallar G (1984) Exploring the articulatory loop. Q J Exp Psychol Sect A 36(2):233-252. https://doi.org/10. 1080/14640748408402157

86. Buchsbaum BR (2013) The role of consciousness in the phonological loop: Hidden in plain sight. Front s in Psychol 4:496. https://doi.org/10.3389/fpsyg.2013.00496

87. Amianto F, Northoff G, Abbate Daga G, Fassino S, Tasca GA (2016) Is anorexia nervosa a disorder of the self? A psychological approach. Front Psychol 7:849. https://doi.org/10.3389/fpsyg. 2016.00849 
88. Oldershaw A, Startup H, Lavender T (2019) Anorexia Nervosa and a lost emotional self: a psychological formulation of the development, maintenance, and treatment of anorexia nervosa. Front Psychol 10:219. https://doi.org/10.3389/fpsyg.2019.00219

89. Bunge SA, Wright SB (2007) Neurodevelopmental changes in working memory and cognitive control. Curr Opin Neurobiol 17(2):243-250. https://doi.org/10.1016/j.conb.2007.02.005

90. Tamnes CK, Walhovd KB, Grydeland H, Holland D, Østby Y, Dale AM, Fjell AM (2013) Longitudinal working memory development is related to structural maturation of frontal and parietal cortices. J Cogn Neurosci 25(10):1611-1623. https://doi.org/10. 1162/jocn_a_00434

91. Andre J, Picchioni M, Zhang R, Toulopoulou T (2016) Working memory circuit as a function of increasing age in healthy adolescence: a systematic review and meta-analyses. Neuroimage Clin 12:940-948. https://doi.org/10.1016/j.nicl.2015.12.002

92. Crone EA, Wendelken C, Donohue S, van Leijenhorst L, Bunge SA (2006) Neurocognitive development of the ability to manipulate information in working memory. Proc Natl Acad Sci 103(24):9315-9320. https://doi.org/10.1073/pnas.0510088103

93. Satterthwaite TD, Wolf DH, Erus G, Ruparel K, Elliott MA, Gennatas ED, Hopson R, Jackson C, Prabhakaran K, Bilker WB, Calkins ME, Loughead J, Smith A, Roalf DR, Hakonarson H, Verma R, Davatzikos C, Gur RC, Gur RE (2013) Functional maturation of the executive system during adolescence. $\mathrm{J}$ Neurosci 33(41):16249-16261. https://doi.org/10.1523/JNEUR OSCI.2345-13.2013

94. Luna B, Marek S, Larsen B, Tervo-Clemmens B, Chahal R (2015) An integrative model of the maturation of cognitive control. Annu Rev Neurosci 38:151-170. https://doi.org/10. 1146/annurev-neuro-071714-034054

95. Lozano-Serra E, Andrés-Perpiña S, Lázaro-García L, CastroFornieles J (2014) Adolescent anorexia nervosa: cognitive performance after weight recovery. J Psychosom Res 76(1):6-11. https://doi.org/10.1016/j.jpsychores.2013.10.009

96. Fonville L, Giampietro V, Surguladze S, Williams S, Tchanturia K (2014) Increased BOLD signal in the fusiform gyrus during implicit emotion processing in anorexia nervosa. NeuroImage: Clin 4:266-273. https://doi.org/10.1016/j.nicl.2013. 12.002

97. Nikendei C, Funiok C, Pfüller U, Zastrow A, Aschenbrenner S, Weisbrod M, Herzog W, Friederich HC (2011) Memory performance in acute and weight-restored anorexia nervosa patients. Psychol Med 41(4):829. https://doi.org/10.1017/S003329171 0001121

98. Dahlenburg SC, Gleaves DH, Hutchinson AD (2019) Anorexia nervosa and perfectionism: a meta-analysis. Int J Eat Disord 52(3):219-229. https://doi.org/10.1002/eat.23009

99. Peat C, Mitchell JE, Hoek HW, Wonderlich SA (2009) Validity and utility of subtyping anorexia nervosa. Int J Eat Disord 42(7):590-594. https://doi.org/10.1002/eat.20717

100. Renwick B, Musiat P, Lose A, DeJong H, Broadbent H, Kenyon M, Loomes R, Watson C, Ghelani S, Serpell L, Richards L (2015) Neuro-and social-cognitive clustering highlights distinct profiles in adults with anorexia nervosa. Int J Eat Disord 48(1):26-34. https://doi.org/10.1002/eat.22366

101. Peterson CB, Pisetsky EM, Swanson SA, Crosby RD, Mitchell JE, Wonderlich SA, Le Grange D, Hill L, Powers P, Crow SJ (2016) Examining the utility of narrowing anorexia nervosa subtypes for adults. Compr Psychiatry 67:54-58. https://doi.org/10. 1016/j.comppsych.2016.02.010

102. Joormann J, Gotlib IH (2008) Updating the contents of working memory in depression: interference from irrelevant negative material. J Abnorm Psychol 117(1):182. https://doi.org/10.1037/ 0021-843X.117.1.182
103. Vytal KE, Arkin NE, Overstreet C, Lieberman L, Grillon C (2016) Induced-anxiety differentially disrupts working memory in generalized anxiety disorder. BMC Psychiatry 16(1):1-9. https://doi.org/10.1186/s12888-016-0748-2

104. Gold JM, Barch DM, Feuerstahler LM, Carter CS, MacDonald AW III, Ragland JD, Silverstein SM, Strauss ME, Luck SJ (2019) Working memory impairment across psychotic disorders. Schizophr Bull 45(4):804-812. https://doi.org/10.1093/schbul/sby134

105. Billingsley-Marshall RL, Basso MR, Lund BC, Hernandez ER, Johnson CL, Drevets WC, McKee PA, Yates WR (2013) Executive function in eating disorders: the role of state anxiety. Int $\mathrm{J}$ Eat Disord 46(4):316-321. https://doi.org/10.1002/eat.22086

106. Lunde AV, Fasmer OB, Akiskal KK, Akiskal HS, Oedegaard KJ (2009) The relationship of bulimia and anorexia nervosa with bipolar disorder and its temperamental foundations. J Affect Disord 115(3):309-314. https://doi.org/10.1016/j.jad.2008.10.012

107. Boraska V, Franklin CS, Floyd JA, Thornton LM, Huckins LM, Southam L, Bulik CM (2014) A genome-wide association study of anorexia nervosa. Mol Psychiatry 19(10):1085-1094. https:// doi.org/10.1038/mp.2013.187

108. McElroy SL, Frye MA, Hellemann G, Altshuler L, Leverich GS, Suppes T, Keck PE, Nolen WA, Kupka R, Post RM (2011) Prevalence and correlates of eating disorders in 875 patients with bipolar disorder. J Affect Disord 128(3):191-198. https://doi.org/ 10.1016/j.jad.2010.06.037

109. Liu JX, Chen YS, Hsieh JC, Su TP, Yeh TC, Chen LF (2010) Differences in white matter abnormalities between bipolar I and II disorders. J Affect Disord 127(1-3):309-315. https:// doi.org/10.1016/j.jad.2010.05.026

110. Pomarol-Clotet E, Alonso-Lana S, Moro N, Sarro S, Bonnin MC, Goikolea JM, Fernandez-Corcuera P, Amann BL, Romaguera A, Vieta E, Blanch J (2015) Brain functional changes across the different phases of bipolar disorder. Br J Psychiatry 206(2):136-144. https://doi.org/10.1192/bjp.bp. 114.152033

111. Wingen M, Kuypers KPC, Ramaekers JG (2007) Selective verbal and spatial memory impairment after 5-HT1A and 5-HT2A receptor blockade in healthy volunteers pre-treated with an SSRI. J Psychopharmacol 21(5):477-485. https://doi.org/10.1177/ 0269881106072506

112. Herrera-Guzmán I, Gudayol-Ferré E, Herrera-Guzmán D, Guàrdia-Olmos J, Hinojosa-Calvo E, Herrera-Abarca JE (2009) Effects of selective serotonin reuptake and dual serotonergicnoradrenergic reuptake treatments on memory and mental processing speed in patients with major depressive disorder. J Psychiatr Res 43(9):855-863. https://doi.org/10.1016/j.jpsychires. 2008.10.015

113. Reilly JL, Harris MS, Keshavan MS, Sweeney JA (2006) Adverse effects of risperidone on spatial working memory in first-episode schizophrenia. Arch Gen Psychiatry 63(11):1189-1197. https:// doi.org/10.1001/archpsyc.63.11.1189

114. Lidow MS, Elsworth JD, Goldman-Rakic PS (1997) Downregulation of the D1 and D5 dopamine receptors in the primate prefrontal cortex by chronic treatment with antipsychotic drugs. J Pharmacol Exp Ther 281(1):597-603

115. Bortolozzi A, Díaz-Mataix L, Scorza MC, Celada P, Artigas F (2005) The activation of 5-HT2A receptors in prefrontal cortex enhances dopaminergic activity. J Neurochem 95(6):1597-1607. https://doi.org/10.1111/j.1471-4159.2005.03485.x

116. Schacht JP (2016) COMT val158met moderation of dopaminergic drug effects on cognitive function: a critical review. Pharmacogenomics J 16(5):430-438. https://doi.org/10.1038/tpj.2016.43

117. Wierenga CE, Ely A, Bischoff-Grethe A, Bailer UF, Simmons AN, Kaye WH (2014) Are extremes of consumption in eating disorders related to an altered balance between reward and 
inhibition? Front Behav Neurosci 8:410. https://doi.org/10.3389/ fnbeh.2014.00410

118. Monteleone AM, Castellini G, Volpe U, Ricca V, Lelli L, Monteleone P, Maj M (2018) Neuroendocrinology and brain imaging of reward in eating disorders: a possible key to the treatment of anorexia nervosa and bulimia nervosa. Prog Neuropsychopharmacol Biol Psychiatry 80:132-142. https://doi.org/10.1016/j. pnpbp.2017.02.020

119. Lipsman N, Woodside DB, Lozano AM (2015) Neurocircuitry of limbic dysfunction in anorexia nervosa. Cortex 62:109-118. https://doi.org/10.1016/j.cortex.2014.02.020

120. Brooks SJ, Dahlberg LS, Swenne I, Aronsson M, Zarei S, Lundberg L, Jacobsson JA, Rask-Andersen M, Salonen-Ros H, Rosling A, Larsson EM, Schiöth HB (2014) Obsessive-compulsivity and working memory are associated with differential prefrontal cortex and insula activation in adolescents with a recent diagnosis of an eating disorder. Psychiatry Res Neuroimaging 224(3):246-253. https://doi.org/10.1016/j.pscychresns.2014.10. 001

121. Sanders N, Smeets PA, van Elburg AA, Danner UN, van Meer F, Hoek HW, Adan RA (2015) Altered food-cue processing in chronically ill and recovered women with anorexia nervosa. Front Behav Neurosci 9:46. https://doi.org/10.3389/fnbeh.2015.00046

122. Horndasch S, Roesch J, Forster C, Dörfler A, Lindsiepe S, Heinrich H, Graap H, Moll GH, Kratz O (2018) Neural processing of food and emotional stimuli in adolescent and adult anorexia nervosa patients. PLoS ONE 13(3):e0191059. https://doi.org/10. 1371/journal.pone.0191059

123. Fladung AK, Schulze UM, Schöll F, Bauer K, Groen G (2013) Role of the ventral striatum in developing anorexia nervosa. Transl Psychiatry 3(10):e315-e315. https://doi.org/10.1038/tp. 2013.88

124. O'Hara CB, Campbell IC, Schmidt U (2015) A reward-centred model of anorexia nervosa: a focussed narrative review of the neurological and psychophysiological literature. Neurosci Biobehav Rev 52:131-152. https://doi.org/10.1016/j.neubiorev.2015. 02.012

125. Södersten P, Bergh C, Leon M, Zandian M (2016) Dopamine and anorexia nervosa. Neurosci Biobehav Rev 60:26-30. https://doi. org/10.1016/j.neubiorev.2015.11.003

126. Nunn K, Frampton I, Fuglset TS, Törzsök-Sonnevend M, Lask B (2011) Anorexia nervosa and the insula. Med Hypotheses 76(3):353-357. https://doi.org/10.1016/j.mehy.2010.10.038

127. Papagno C, Comi A, Riva M, Bizzi A, Vernice M, Casarotti A, Fava E, Bello L (2017) Mapping the brain network of the phonological loop. Hum Brain Mapp 38(6):3011-3024. https://doi. org/10.1016/j.neubiorev.2016.09.032

128. Scherf KS, Sweeney JA, Luna B (2006) Brain basis of developmental change in visuospatial working memory. J Cogn Neurosci 18(7):1045-1058. https://doi.org/10.1162/jocn.2006.18.7.1045

129. Lycke C, Specht K, Ersland L, Hugdahl K (2008) An fMRI study of phonological and spatial working memory using identical stimuli. Scand J Psychol 49:393-401. https://doi.org/10.1111/j. 1467-9450.2008.00672.x

130. Kullmann S, Giel KE, Teufel M, Thiel A, Zipfel S, Preissl H (2014) Aberrant network integrity of the inferior frontal cortex in women with anorexia nervosa. NeuroImage Clin 4:615-622. https://doi.org/10.1016/j.nicl.2014.04.002

131. Marvel CL, Desmond JE (2012) From storage to manipulation: how the neural correlates of verbal working memory reflect varying demands on inner speech. Brain and Lang 120(1):42-51. https://doi.org/10.1016/j.bandl.2011.08.005
132. Alderson-Day B, Weis S, McCarthy-Jones S, Moseley P, Smailes D, Fernyhough C (2016) The brain's conversation with itself: neural substrates of dialogic inner speech. Soc Cogn Affect Neurosci 11(1):110-120. https://doi.org/10.1093/scan/nsv094

133. Smith KE, Mason TB, Johnson JS, Lavender JM, Wonderlich SA (2018) A systematic review of reviews of neurocognitive functioning in eating disorders: the state-of-the-literature and future directions. Int J Eat Disord 51(8):798-821. https://doi.org/ 10.1002/eat.22929

134. National Institute for Health and Care Excellence (2017). Eating disorders: recognition and treatment (NICE Guideline No. 69). https://www.nice.org.uk/guidance/ng69

135. Davies H, Tchanturia K (2005) Cognitive remediation therapy as an intervention for acute anorexia nervosa: a case report. Eur Eat Disord Rev 13(5):311-316. https://doi.org/10.1002/erv.655

136. Tchanturia K, Giombini L, Leppanen J, Kinnaird E (2017) Evidence for cognitive remediation therapy in young people with anorexia nervosa: Systematic review and meta-analysis of the literature. Eur Eat Disord Rev 25(4):227-236. https://doi.org/ 10.1002/erv.2522

137. Alvarado-Sánchez N, Alvarez-Rayón G, Mancilla-Díaz J (2019) Cognitive remediation therapy in Mexico as a treatment for anorexia nervosa: a case study. Eat Disord 27(2):230-252. https:// doi.org/10.1080/10640266.2019.1591849

138. Giombini L, Moynihan J, Turco M, Nesbitt S (2016) Evaluation of individual cognitive remediation therapy (CRT) for the treatment of young people with anorexia nervosa. Eat Weight Disord 22(4):667-673. https://doi.org/10.1007/s40519-016-0322-4

139. Mercado D, Schmidt U, O'Daly OG, Campbell IC, Werthmann J (2020) Food related attention bias modification training for anorexia nervosa and its potential underpinning mechanisms. $\mathrm{J}$ Eat Disord 8(1):1. https://doi.org/10.1186/s40337-019-0276-9

140. Matthijssen SJMA, Heitland I, Verhoeven LCM, van den Hout MA (2019) Reducing the emotionality of auditory hallucination memories in patients suffering from auditory hallucinations. Front Psychiatry 18(10):637. https://doi.org/10.3389/fpsyt.2019. 00637

141. Dolhanty J, Greenberg LS (2009) Emotion-focused therapy in a case of anorexia nervosa. Clin Psychol Psychother 16(4):336382. https://doi.org/10.1080/14779757.2014.910132

142. Hampshire K, Tierney S, Varese F, Haddock G, Saeidi S, Fox JR (2020) The development and assessment of a scale to measure the experience of an anorexic voice in anorexia nervosa. Psychother Clin Psychol. https://doi.org/10.1002/cpp.2481

143. Owen AM, McMillan KM, Laird AR, Bullmore E (2005) N-back working memory paradigm: a meta-analysis of normative functional neuroimaging studies. Hum Brain Mapp 25(1):46-59. https://doi.org/10.1002/hbm.20131

144. Soveri A, Antfolk J, Karlsson L, Salo B, Laine M (2017) Working memory training revisited: a multi-level meta-analysis of n-back training studies. Psychon Bull Rev 24(4):1077-1096. https://doi. org/10.3758/s13423-016-1217-0

145. Miyake A, Friedman NP, Emerson MJ, Witzki AH, Howerter A, Wager TD (2000) The unity and diversity of executive functions and their contributions to complex "Frontal Lobe" tasks: a latent variable analysis. Cogn Psychol 41(1):49-100. https://doi.org/10. 1006/cogp.1999.0734

146. Lopez C, Stahl D, Tchanturia K (2010) Estimated intelligence quotient in anorexia nervosa: a systematic review and metaanalysis of the literature. Gen Psychiatry Ann. https://doi.org/ $10.1186 / 1744-859 X-9-40$ 
147. Schneider W, Niklas F (2017) Intelligence and verbal short-term memory/working memory: their interrelationships from childhood to young adulthood and their impact on academic achievement. J Intell 5(2):26. https://doi.org/10.3390/jintelligence50 20026

148. Keski-Rahkonen A, Mustelin L (2016) Epidemiology of eating disorders in Europe: prevalence, incidence, comorbidity, course, consequences, and risk factors. Curr Opin Psychiatry 29(6):340345. https://doi.org/10.1097/YCO.0000000000000278

Publisher's Note Springer Nature remains neutral with regard to jurisdictional claims in published maps and institutional affiliations. 